\title{
Article
}

\section{Self-regulation in endurance sports: theory, research, and practice}

McCormick, Alister, Meijen, Carla, Anstiss, Paul A and Massey, Hollie

Available at http://clok.uclan.ac.uk/22761/

McCormick, Alister, Meijen, Carla, Anstiss, Paul A and Massey, Hollie ORCID: 0000-0002-9793-8702 (2019) Self-regulation in endurance sports: theory, research, and practice. International Review of Sport and Exercise Psychology, 12 (1). pp. 235-264. ISSN 1750-984X

It is advisable to refer to the publisher's version if you intend to cite from the work. http://dx.doi.org/10.1080/1750984X.2018.1469161

For more information about UCLan's research in this area go to http://www.uclan.ac.uk/researchgroups/ and search for <name of research Group>.

For information about Research generally at UCLan please go to http://www.uclan.ac.uk/research/

All outputs in CLoK are protected by Intellectual Property Rights law, including Copyright law. Copyright, IPR and Moral Rights for the works on this site are retained by the individual authors and/or other copyright owners. Terms and conditions for use of this material are defined in the policies page.

\section{CLoK}

Central Lancashire online Knowledge www.clok.uclan.ac.uk

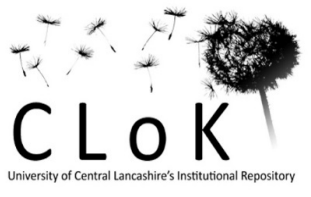




\section{SELF-REGULATION IN ENDURANCE SPORTS}

1

2 There is considerable research interest in psychological aspects of endurance performance. Until 3

4 recently, research typically lacked a theoretical underpinning, and contemporary research is particularly informed by the psychobiological model of endurance performance. In this critical review, we propose that psychological theories relating to self-regulation, particularly self-efficacy theory and the process model of emotion regulation, could shed more light on how endurance performance is determined and lead to additional understanding of how psychological interventions can be used. We argue that people encounter fewer stressors in most experimental studies than are encountered before and during real-life events. In addition, we argue that most research conducted to date has focused on the forethought and performance phases of self-regulation, rather than the self-reflection phase, and research has not considered the cyclical nature of self-regulation. We also argue that if research participants are not endurance athletes, then their motivation may not be self-determined and self-regulatory learning may not take place. Recommendations are given for future research, and evidence-based guidance is offered on enhancing performance and improving the quality of experience for endurance athletes. Keywords: Emotion regulation; endurance performance; psychobiological model; self-efficacy; stressors 


\section{SELF-REGULATION IN ENDURANCE SPORTS}

\section{Introduction to Endurance Performance}

A vast number of people participate in endurance events at elite and sub-elite levels. At the elite level, athletes compete in major competitions in many sport events involving endurance, including summer and winter Olympic events: athletics (e.g., 10,000 metres); indoor and open-water swimming (e.g., 800 metre freestyle, marathon swim); track, road, and mountain cycling; triathlon; rowing; modern pentathlon; cross-country skiing; biathlon; and speed skating. Although each type of event and competitive distance differs in its physical, technical, logistical, and psychological demands (Taylor, 1995), endurance events commonly require the athlete to persevere in continuous, dynamic, and wholebody exercise tasks that are performed over middle or long distances (Burnley \& Jones, 2007; McCormick, Meijen, \& Marcora, 2015). At sub-elite levels, endurance events are popular with competitive recreational athletes. Further, thousands of people participate in endurance events (e.g., 5 $\mathrm{km}$ and $10 \mathrm{~km}$ runs, half-marathons and marathons, triathlons, sportives) for reasons other than competition, such as to engage in more physical activity, as a personal challenge, to accompany a friend, or to raise money for charity (e.g., Lane, Murphy, \& Bauman, 2008). Psychology research on endurance is relevant to people involved in endurance sports at each of these elite and sub-elite levels.

Participation in endurance events is characterised by some common demands (McCormick, Meijen, \& Marcora, 2016). First, endurance athletes experience various exercise-related sensations during training and events, such as muscle pain (aching and burning muscles), injury-related pain, heavy breathing, and cramping discomfort that make it difficult for the athlete to continue (Christensen, Brewer, \& Hutchinson, 2015; Hollander \& Acevedo, 2000; Holt, Lee, Kim, \& Klein, 2014; Kress \& Statler, 2007; McCormick et al., 2016; McCormick, Meijen, \& Marcora, 2018; Samson, Simpson, Kamphoff, \& Langlier, 2017; Schumacher, Becker, \& Wiersma, 2016; Simpson, Post, Young, \& Jensen, 2014). Second, endurance athletes need to make difficult pacing decisions to achieve their performance and outcome goals, such as to finish, to achieve a specified time, or to achieve a position in the standings. If they perform at a pace that is too fast, they risk experiencing exhaustion before the end of the event and therefore not finishing or achieving a time below their capability; if they perform at a pace that is too slow, they risk achieving a time below their capability or failing to meet cut-off times in longer events. In head-to-head competitive events, endurance athletes also need to make pacing 


\section{SELF-REGULATION IN ENDURANCE SPORTS}

decisions in relation to other performers (Hettinga, Konings, \& Pepping, 2017; Konings, Schoenmakers, Walker, \& Hettinga, 2016; McCormick et al., 2016; Micklewright, Kegerreis, Raglin, \& Hettinga, 2017; Renfree, Carmo, Martin, \& Peters, 2015; Renfree, Martin, Micklewright, \& St Clair Gibson, 2014; Williams, Jones, Sparks, Marchant, et al., 2015). These pacing decisions are difficult because the performance environment is dynamic, there are many relevant cues to consider, athletes do not know the current physiological capacity of their competitors, and decisions often need to be made quickly and under pressure (Davies et al., 2016; Edwards \& Polman, 2013; Renfree et al., 2014; Smits, Pepping, \& Hettinga, 2014). Third, like athletes from other sports, endurance athletes encounter a range of competitive, organisational, and personal stressors before and during events (Hollander \& Acevedo, 2000; Holt et al., 2014; McCormick et al., 2016; Nicholls, Levy, Grice, \& Polman, 2009; O’Neil \& Steyn, 2007; Schumacher et al., 2016). Competitive stressors relate to competitive performance (e.g., event preparation, injuries, pressure to perform, underperforming, performance expectations, selfpresentation, rivalry), organisational stressors relate to the sport organisation that athletes operate within (e.g., leadership and personal issues, cultural and team issues, logistical and environmental issues, performance and personal issues), and personal stressors relate to personal "non-sporting" life events (e.g., the work-life interface, family issues, the death of a significant other) (Sarkar \& Fletcher, 2014). Although some stressors are event-specific (e.g., tidal conditions in open-water swimming), other stressors are commonly encountered across many endurance events (e.g., weather, equipment, nutrition, hydration). As discussed later in the review (Emotion Regulation section), stressors can elicit emotional responses that are helpful or harmful to an endurance athlete's performance.

Independent of whether a person competes in endurance events or participates without competing, psychological factors can influence how well they perform (for a review, see McCormick et al., 2015). Some psychological interventions, such as psychological skills training, consistently improve endurance performance (e.g., Blanchfield, Hardy, de Morree, Staiano, \& Marcora, 2014). In addition, some psychological factors, such as mental fatigue and emotion suppression, can undermine endurance performance (Van Cutsem et al., 2017; Wagstaff, 2014). These findings demonstrate that people involved in endurance sports such as sport psychology practitioners, endurance athletes, and coaches could use psychological research to enhance performance. Research that has examined the 


\section{SELF-REGULATION IN ENDURANCE SPORTS}

1 effects of psychological interventions on endurance performance, however, has typically lacked a

2 theoretical basis. In fact, only 11 of the 46 studies (24\%) included in a recent systematic review

3 (McCormick et al., 2015) appeared to be informed by psychological theory. Moreover, as only $48 \%$ of

4 the studies included in the systematic review measured psychological variables, the psychological

5 mechanisms that could explain the intervention-performance relationship were unclear in most studies.

6 Additional theoretically-informed research is needed to increase understanding of how psychological

7 interventions affect the performances of endurance athletes. Through understanding these mechanisms

8 and targeting the mechanisms with interventions, practitioners, athletes, and coaches could achieve

9 greater and more consistent intervention effects (Michie \& Prestwich, 2010). In addition, theoretically-

informed research could play a role in identifying moderating variables, such as the characteristics of

an endurance athlete or specific competitive situations, that influence the direction and size of intervention effects. Ultimately, theoretically-informed research could help sport psychology practitioners, athletes, and coaches to optimally use psychological interventions so that they are of most benefit to performance in endurance events.

The psychobiological model of endurance performance is a predominant theory applied in psychological intervention research on endurance performance. The psychobiological model is based on motivational intensity theory, which is a theory that explains effort mobilisation in goal pursuit (Brehm \& Self, 1989; Richter, Gendolla, \& Wright, 2016). A main proposal of the psychobiological model is that perception of effort (how effortful, heavy, and strenuous the exercise feels; Marcora, 2010) and potential motivation (the greatest amount of effort that a person would be willing to offer to satisfy a motive; Brehm \& Self, 1989) are the main determinants of endurance performance. A person's perception of effort is proposed to reflect their conscious awareness of central motor commands sent to the locomotor and respiratory muscles (Marcora, 2009). Potential motivation is determined by factors traditionally associated with motive strength such as a person's needs (e.g., financial needs, achievement needs), potential outcomes of an instrumental behaviour (e.g., incentives such as the opportunity to win a medal or achieve a personal best time, aversive outcomes such as pain), and the perceived probability that a successfully-executed behaviour will satisfy a need or produce a desired outcome (e.g., attainability of goals) (Brehm \& Self, 1989). For example, elite track-and-field athletes 


\section{SELF-REGULATION IN ENDURANCE SPORTS}

have reported being highly driven by their personal task and ego goals, and the sense of accomplishment and recognition they got when they achieved them, and they reported strong belief in their ability to achieve their goals (Mallett \& Hanrahan, 2004).

When performing at a fixed or incremental workload until exhaustion, perception of effort increases with time (e.g., Noble \& Noble, 2000). The psychobiological model proposes that performers consciously decide to give up under one of two circumstances: (1) they perceive the effort required to continue is greater than they are willing to offer, or (2) they believe they have offered their maximal effort and perceive continuing as impossible. During time trials, when athletes can adjust their pace, the model proposes that endurance athletes consciously make pacing decisions to control the increase in their perception of effort over time, so that they experience the greatest amount of effort they are willing to offer at the end of the event (Marcora \& Bosio, 2007). As most endurance events involve head-tohead competition, the psychobiological model proposes that additional psychological factors (e.g., individual and team strategy, behaviour of other competitors) influence pacing decisions and performance in endurance events (Marcora, 2015). Research testing predictions of the psychobiological model has started to accumulate. It is therefore timely to critically review the psychobiological model and its experimental support, and to consider additional theories that could shed more light on how endurance performance is determined.

Few psychological theories have been applied to psychological intervention research on endurance performance. In addition to the psychobiological model, there are other theories specific to exercise performance that explain how endurance performance is determined, and there is much critical debate between proponents of theories (e.g., Inzlicht \& Marcora, 2016; Micklewright \& Parry, 2010; Shephard, 2009). Some of these theories are firmly grounded in exercise physiology (inhibitory afferent feedback model, Amann \& Secher, 2010; oxygen uptake kinetics, Burnley \& Jones, 2007; critical power concept, Jones, Vanhatalo, Burnley, Morton, \& Poole, 2010; maximum oxygen consumption, lactate threshold, and economy/efficiency, Joyner \& Coyle, 2008), and others consider the interplay between physiological and psychological factors (central governor model, Noakes, 2012; integrative governor theory, St Clair Gibson, Swart, \& Tucker, 2018; anticipatory feedback model, Tucker, 2009). The latter theories also identify effort-related perceptions as influencing endurance performance, although the 


\section{SELF-REGULATION IN ENDURANCE SPORTS}

1 definitions, neurophysiological bases, and performance-related mechanisms of these effort-related

2 perceptions vary and are critically debated (e.g., Marcora, 2009). Nevertheless, from a psychology

3 perspective, we argue that these theories have a limited psychological theoretical foundation that sport

4 and exercise psychology researchers and practitioners, athletes, and coaches could practically apply to

5 enhance performance. In this article, we propose that additional psychological theories relating to self-

6 regulation could valuably inform intervention research. Although these theories are not specific to

7 endurance activity, we argue that they do not need to be, as endurance events share important

8 commonalities with other sport events and other areas of goal pursuit.

\section{Aims of the Review}

Considering the substantial numbers of endurance event participants at elite and sub-elite levels, the limited number of theoretically-informed psychological intervention studies on endurance performance, and the growing research on the psychobiological model, it is timely to review what we know and how to build on this to inform practice. The overarching purpose of this review is to stimulate theoretically-informed intervention research in the area of endurance performance. This review has four aims. The first aim is to critically review the contribution of the psychobiological model in explaining endurance performance, particularly considering the ecological validity of research that supports it. The second aim is to stimulate and direct theoretically-informed psychological intervention research on endurance performance. Building on the second aim, and based on the demands of endurance performance, the third aim is to apply two relevant psychological theories relating to self-regulation (self-efficacy theory and the process model of emotion regulation), and to review research relating to these theories in the context of endurance performance. The fourth aim is to provide theoreticallyinformed and evidence-based intervention suggestions for enhancing performance and improving the quality of experience for endurance athletes. To achieve these aims, a critical literature review is presented.

\section{Definitions and Literature Search}




\section{SELF-REGULATION IN ENDURANCE SPORTS}

Within this review, we consider endurance tasks and events to involve performing continuous, dynamic, and whole-body exercise tasks (e.g., running, cycling, swimming, rowing) over middle or long distances, at sub-maximal intensities. Studies have measured endurance performance by measuring the amount of time that it takes a person to complete a set distance or amount of work ("constant-work tests" or "time trials"), the highest velocity or power-output increment that a person can reach before exhaustion ("incremental tests"), the amount of time that a set workload can be maintained ("constantworkload" or "time-to-exhaustion tests"), the distance or the amount of work that a person can complete in a set duration ("constant-duration tests"), and performance outcomes in competition (McCormick et al., 2015). Although the performance distances and times of endurance events can vary substantially, we reviewed studies where performances lasted for at least 75 seconds (McCormick et al., 2015) (equivalent to 800 metres in running and 200 metres in freestyle swimming), to reflect the predominant contribution of the aerobic energy system (Gastin, 2001). So that the review of theories reflects the research conducted on them within the endurance context, a systematic literature search was conducted. A database search (Scopus, SportDiscus, PsychInfo) was conducted in October 2017 to locate peerreviewed studies that (1) contain "psychobiological model", "self-efficacy", "self-regulation", or "emotion regulation" in the title, abstract, subjects, or keywords and (2) contain an endurance-related word in the title, abstract, subjects, or keywords ("endurance", "time trial", "time-to-exhaustion", "running”, “cycling”, “swimming”, “rowing”, “triathlon”, “speedskating”, “racewalking”, or “crosscountry skiing"). A previous systematic review (McCormick et al., 2015), and forward citation searches of relevant papers in Scopus and Google Scholar, were also used to locate relevant studies. Located studies were scrutinised in relation to the review aims. Broader literature is included where relevant.

\section{Psychobiological Model}

Applying the psychobiological model, any factor that reduces perception of effort or increases potential motivation should enhance endurance performance, and any factor that increases perception of effort or reduces potential motivation should undermine endurance performance (Marcora et al., 2008). In the next paragraphs, we will review experiments that generally support these predictions. As previously stated, however, relatively few experimental studies in this research area have had a clear theoretical basis. Consequently, few studies have examined psychological mechanisms that could 


\section{SELF-REGULATION IN ENDURANCE SPORTS}

explain changes in endurance performance, by measuring motivation, perception of effort, or other mediating variables. Mechanisms therefore cannot be determined in many studies.

Regarding perception of effort, a change in perception of effort could be seen through a change in ratings of perceived exertion (RPE) when performing at a fixed workload, or through a change in pace without a change in RPE (e.g., increasing power output in a cycling time trial without reporting higher RPE). Motivational self-talk (Barwood, Corbett, Wagstaff, McVeigh, \& Thelwell, 2015; Blanchfield et al., 2014) and psychological skills training packages (Barwood, Thelwell, \& Tipton, 2008) appear to reduce perception of effort, and they have been shown to improve endurance performance. Another study, however, found that using motivational self-talk when performing in the heat did not reduce perception of effort and, instead, helped performers to perform for a longer duration when they reached near-maximal levels of effort (Wallace et al., 2017). In addition, mental fatigue (Van Cutsem et al., 2017) and emotion suppression (Wagstaff, 2014) increase perception of effort and detrimentally affect endurance performance.

An area of contention, however, is the proposal that perception of effort is the only exerciserelated sensation that substantially contributes to pacing and endurance performance when athletes are uninjured. Mauger (2014) argued that exercise-induced muscle pain and discomfort also contribute to pacing decisions and endurance performance, particularly during high-intensity exercise. This argument is consistent with self-reports by endurance athletes (e.g., Kress \& Statler, 2007), although endurance athletes' use of pain-related words are often broad and partly reflect other exercise-related sensations such as effort (e.g., Simpson et al., 2014). Although perceptions of effort and pain during endurance exercise are correlated and increase alongside one another (e.g., Mauger, Jones, \& Williams, 2010), there is some research support for the independent role of pain tolerance in cycling performance (Astokorki \& Mauger, 2017). Affective valence (i.e., pleasure or displeasure) (Hardy \& Rejeski, 1989) is an additional exercise-related sensation that could influence pacing and performance in endurance events (Ekkekakis, Hargreaves, \& Parfitt, 2013; Ekkekakis, Parfitt, \& Petruzzello, 2011; Venhorst, Micklewright, \& Noakes, 2017). Performing feels increasingly unpleasant between the lactate and ventilatory thresholds and maximal oxygen uptake (Ekkekakis et al., 2011), and feelings of displeasure could influence pacing decisions, particularly in populations that are inexperienced or non-competitive. 


\section{SELF-REGULATION IN ENDURANCE SPORTS}

1 Although some research has examined affective responses during endurance performance (Jones et al.,

2 2014), research has yet to establish whether it has a primary role in determining pace, independent of

3

4

5

6

7

8 perception of effort. Measuring perception of effort, perceived pain, and affective valence as standard perceptual measures could help to clarify the role that each plays in determining pacing and endurance performance (Mauger, 2014). Furthermore, potential differences in the roles that these three variables play in determining pacing and performance between trained and untrained populations, between different endurance sports, and at different exercise intensities need to be considered. When measuring perception of effort, perceived pain, and affective valence, they should be appropriately defined and measured (see Ekkekakis, 2012; Pageaux, 2016).

Regarding potential motivation, a range of motivational interventions improve endurance performance. Interventions such as verbal encouragement (e.g., Moffatt et al., 1994), head-to-head competition (e.g., Corbett et al., 2012), goal setting (e.g., Theodorakis et al., 1998), performing in front of a person of the opposite sex (Jung, Ferrari, Goebel, \& Figulla, 2009), pre-performance motivational shouting exercises (Donohue et al., 2006), and pre-performance music (Smirmaul, dos Santos, \& da Silva Neto, 2015) could be expected to increase a person's potential motivation, and they do improve endurance performance (for a review, see McCormick et al., 2015). A common limitation of research in this area, however, is that studies generally have not included a manipulation check to determine whether the intervention had the anticipated effect. Many of these studies also have not explored potential intervention-performance mechanisms (cf. Smirmaul et al., 2015), making it difficult to attribute the intervention effects conclusively to motivation. There is also evidence that listening to motivational music while performing can improve endurance performance (Karageorghis \& Priest, 2012), but because there is little homogeneity across studies conducted on music, it is difficult to unravel the effects of different types of music on motivation and perception of effort during endurance exercise at different intensities.

Although potential motivation could be measured before performance using motivation questionnaires and during performance using the highest rating of perceived exertion, methods of examining changes in motivation levels that occur during performance (e.g., in response to stressors) have not been established. Innovative motivation measures are needed for the endurance research 


\section{SELF-REGULATION IN ENDURANCE SPORTS}

context, and these could include combinations of psychophysiological measures (e.g., changes in RPE during self-paced tasks), behavioural measures (e.g., changes in power output during self-paced tasks), and qualitative data (e.g., think-aloud protocol, post-performance interview) (Clancy, Herring, MacIntyre, \& Campbell, 2016). Social desirability challenges associated with self-reporting motivation (particularly without anonymity, e.g., King \& Bruner, 2000) also merit consideration and innovative solutions.

Research reviewed in the Introduction to Endurance Performance section demonstrates that people encounter a range of stressors in competitive and non-competitive endurance events. The vast majority of research on psychological interventions for endurance performance, however, has been conducted away from events. Indeed, 29 of 46 studies (63\%) included in the McCormick et al. (2015) systematic review were conducted in a laboratory, $15(33 \%)$ were conducted in field settings that were not real-life events (although three of them simulated competitions), and only two (4\%) were conducted at real-life events. In laboratory and non-competitive field settings, athletes would not encounter many of the stressors that are encountered during endurance events. Further, encountering stressors outside of a real-life event would be less likely to put an athlete's goals at stake and elicit a potentially debilitative emotional response (Martinent \& Ferrand, 2015; Uphill \& Jones, 2007). Moreover, encountering stressors in a setting such as a laboratory that does not reflect an athlete's normal training and race conditions is not expected to play a large role in an athlete's self-efficacy because the stressors are not as threatening to their goal achievement. For example, endurance athletes may rely on vicarious experiences to inform their self-efficacy, such as comparing their performance to others they are competing against. Therefore, we believe that a key characteristic of endurance events is not present in the experimental studies that support the psychobiological model. As explained in the following sections, we believe that psychological mechanisms relating to encountered stressors play a key role in determining endurance performance in real-life events. Although a performer's response to these stressors could influence their motivation, perception of effort, or concentration on their pacing (e.g., Martinent \& Ferrand, 2009)—factors that would be predicted to influence performance, when applying the psychobiological model —we argue that these mechanisms are only sufficiently appreciated by considering the psychobiological model in conjunction with other theories. Within this article, we argue 


\section{SELF-REGULATION IN ENDURANCE SPORTS}

that self-regulation theories relating to self-efficacy and emotion regulation could shed additional light on how endurance performance is determined, and lead to improved understanding of how psychological interventions can be used to benefit performance and quality of experience at endurance events.

\section{Self-Regulation}

Endurance activities typically require performers to engage in processes that guide them towards, or away from, states or goals. This can be during a race, but also in training and developmental stages that include pre-race situations and tapering. Examples of these processes relate to the effort a performer is willing to offer, how to manage pain and discomfort, and decisions about whether to continue and at what pace to continue. These processes, where individuals alter their own responses or inner states in a goal-directed manner, encapsulate self-regulation (Carver \& Scheier, 2009). In this review, we are particularly inspired by self-regulation as a framework that underpins action-planning, learning, and development in endurance performance activities (for further reading on different approaches to self-regulation, we refer the reader to Boekaerts, Pintrich, \& Zeider, 2000; Vohs \& Baumeister, 2017). We draw on the definition of self-regulation as "self-generated thoughts, feelings and actions that are planned and cyclically adapted to the attainment of personal goals" (Zimmerman, 2000, p. 14), and we acknowledge the importance of self-oriented feedback loops occurring at different phases of self-regulated learning (Zimmerman, 2000). We note that, although motivation and selfregulation are "close friends" (Boekaerts, 2010), these concepts are not the same. Rather, taking into account the volitional nature of self-regulation, one can consider motivation to be needed for the mobilisation of self-regulation (Kuhl, 2000). That is, taking part in endurance activities per se does not mean that an endurance athlete engages in self-regulation.

Self-regulation enables an individual to monitor and adjust their goal-directed activities in different situations and contexts using self-oriented feedback loops. A self-oriented feedback loop involves the evaluation of one's behaviour in relation to their personal standards and the environment (Zimmerman, 2000). Self-regulation can be considered to involve three phases: forethought, performance, and self-reflection (Zimmerman, 2000, 2002). This view of self-regulation is cyclical and incorporates the self-oriented feedback processes, which is underlined by the inclusion of a self- 


\section{SELF-REGULATION IN ENDURANCE SPORTS}

1 reflection stage, and endurance athletes can employ a range of metacognitive skills such as planning,

2 monitoring, and reviewing their thoughts in these three phases (see Brick, MacIntyre, \& Campbell,

3 2015). Metacognition is often referred to as "thinking about thinking" (Miller, Kessel, \& Flavell, 1970,

4 p. 613), and it is an important aspect of self-regulation. Metacognition traditionally emphasised the

5 development of cognitive structures, and reflects the activation of thoughts and behaviours to achieve

6 goals. This is where the link with self-regulation can be drawn, that is, where metacognition traditionally

7 is considered to be about the activation of cognitive structures, self-regulation emphasises the

8 interaction of the person and environment, and subsequent goal-driven behaviour (Dinsmore,

9 Alexander, \& Loughlin, 2008). For example, when considering endurance performance, the metacognitive skill of establishing a preferred pacing strategy can influence behaviour in a particular context, such as how much effort a cyclist is putting into a one-hour time trial (Brick, MacIntyre, \& Campbell, 2016).

The first phase of self-regulation is the forethought phase. This phase refers to processes and beliefs that happen before the activity takes place, such as planning, goal setting, and activation of strategies such as identifying a pacing strategy. Two major classes of processes take place in the forethought phase: task analysis and self-motivation beliefs (Zimmerman, 2000). Task analysis involves goal setting and strategic planning, such as breaking a task down into different parts. An example of a task-analysis process is breaking a marathon down into different stages (or "chunks") with a different goal for each of these stages. Elite endurance athletes have also reported planning race objectives, planning race tactics and pacing, and planning their use of cognitive strategies (e.g., to focus on breathing), race support needs, and nutritional strategies (Brick et al., 2015). Self-motivation beliefs involve self-efficacy beliefs, outcome expectations, and intrinsic interest. For example, a cyclist who values the activity for what it is, rather than for what they may gain from it such as fitness or beating others, and who believes they have the capability to keep going despite high exertion and pain, will be more motivated to take part in cycling in a self-regulated manner.

The performance phase refers to processes that happen during the activity or behavioural implementation, and the two major classes of processes are self-control and self-observation. Selfcontrol processes are particularly relevant. In the forethought phase, an endurance athlete selects 


\section{SELF-REGULATION IN ENDURANCE SPORTS}

methods or strategies; in the self-control performance phase, they deploy them. A diverse range of these (metacognitive) strategies are used by endurance athletes in the performance phase (Brick et al., 2015), and they include using imagery to help with pacing decisions or unhelpful emotions, strategically using self-talk statements, and strategically focusing attention. Finally, the self-reflection phase refers to processes that occur after the behavioural implementation. The two major classes of processes in the self-reflection phase are self-judgment and self-reaction. Self-judgments include comparisons of selfobserved performances against a standard (e.g., prior performance, another person's performance), and causal attributions for success or failure. Self-satisfaction is a key form of self-reaction, and it can influence the effort that an athlete is willing to put into future activities. For example, if an athlete is dissatisfied with their performance or feels guilty about being unable to train enough because of other commitments, their willingness and motivation to put in effort in the future could be reduced. The threestage approach to self-regulation is cyclical; the self-reflections that take place inform subsequent forethought processes and beliefs (Zimmerman, 2002).

This view emphasises that self-regulation is a process that involves an individual taking actions that require regulation of thoughts, feelings, and behaviours that a person has influence over, whilst also considering what is going on in the environment. Much of the application of self-regulated learning in sporting contexts has focused on motor skill learning, particularly in relation to fine motor skills. Broadly, research findings suggest that more experienced athletes engage in more self-regulated learning behaviours (Cleary \& Zimmerman, 2001) and that there is a positive relationship between selfregulated learning and performance (Cleary, Zimmerman, \& Keating, 2006; Kitsantas \& Zimmerman, 2002). There is research emerging that demonstrates the potential to apply self-regulated learning to endurance performance. This is relevant because in endurance activities, participants constantly make decisions about goal-driven processes such as whether to slow down or speed up based on how they feel physically and emotionally, and based on what is going on in their environment such as weather conditions and behaviours of other participants (Hettinga et al., 2017; Renfree et al., 2014). In terms of self-regulation, it is also important to understand and reflect on what is going on in the environment and, from a social-cognitive perspective, aspects such as modelling (e.g., seeing others succeed) can inform the processes that we engage in to move towards, or away from, a desired state or goal. Although 


\section{SELF-REGULATION IN ENDURANCE SPORTS}

1

research in endurance performance is scarce, Elferink-Gemser and Hettinga (2017) proposed that selfregulated learning can benefit endurance performance through a focus on developing pacing skills. Other researchers explored the role of motivational and volitional factors, such as action-planning, in self-regulated running training for untrained participants during a one-year period, using a health behaviour change approach, and found that those who did not end up running a marathon distance used less action planning at the start of the training and their action planning fluctuated more over time (Scholz, Nagy, Schüz, \& Ziegelmann, 2008). Overall, the fluctuation of volitional variables, as well as fluctuation of self-efficacy, seemed to be unhelpful for running performance (Scholz et al., 2008). To make the link with self-regulated learning, it appears that the initial lack of action planning in the forethought phase of self-regulation affected the self-regulatory skills in the performance stage where they may have found it difficult to adjust their behaviour.

Below, we propose that two psychological theories relating to self-regulation (self-efficacy theory and the process model of emotion regulation) could shed additional light on how endurance performance is determined, and lead to additional, efficacious interventions for endurance events. We do not believe that these are the only theories relating to self-regulation that could inform future research. Instead, we aim to stimulate theoretically-informed intervention research and argue that these theories could fit the endurance context well.

\section{Self-Efficacy}

Social-cognitive theory outlines that individuals possess a series of intertwined beliefs about themselves and the world around them (Wood \& Bandura, 1989). Central to these beliefs, and critical for self-regulation, are self-efficacy beliefs (Bandura, 1997). Self-efficacy refers to "beliefs in one's capabilities to mobilise the motivation, cognitive resources, and courses of action needed to meet given situational demands" (Wood \& Bandura, 1989, p. 408). It represents a self-appraisal of whether an individual can, as opposed to will (an intention belief) or has (a previous experience). These beliefs are derived through the integration and appraisal of several sources of information such as past performance experiences, vicarious influences, social persuasions, and perceptions of physiological and emotional states (Bandura, 1997). Self-efficacy beliefs are not global traits, instead they are tied to specific domains of functioning, and fluctuate as new information is collected and processed. 


\section{SELF-REGULATION IN ENDURANCE SPORTS}

One key assumption of self-efficacy theory is that what people perceive themselves to be capable of is often a better predictor of behaviour and performance than what they are objectively capable of (Bandura, 1997). These perceptions of capability cannot supersede ability, but rather individuals must perceive themselves to be capable if they are to make full use of their potential abilities and skills (Bandura, 1997). Self-efficacy influences the amount of effort an individual is willing to expend and their perseverance when faced with difficulties and setbacks (Bandura, 1997). This is relevant to the psychological demands of endurance performance, such as dealing with pain and discomfort, pacing, a range of environmental stressors, and motivation to continue (e.g., McCormick et al., 2016). When examining the relationship between self-efficacy, self-regulation, and endurance performance, it is important to consider how self-efficacy may fit into Zimmerman's (2000) three phases of self-regulation (forethought, performance, and self-reflection), and the next three paragraphs explore the role, that we propose, self-efficacy may play in these phases.

The forethought phase involves the setting of goals for the upcoming activity, and self-efficacy beliefs have been consistently linked with the process of goal setting and goal pursuit (Bandura, 1997; Locke \& Latham, 1985). Individuals high in self-efficacy are more likely to set themselves challenging goals (Locke \& Latham, 2002), continue striving towards these goals despite setbacks (Bandura, 1997), and have increased belief in their levels of goal attainment (Kane, Marks, Zaccaro, \& Blair, 1996). Challenging and difficult goals are, in turn, associated with increased willingness to expend effort (Weinberg, Gould, Yukelson, \& Jackson, 1981) and increased levels of motivation (Howle, Dimmock, \& Jackson, 2016; Hutchinson, Sherman, Martinovic, \& Tenenbaum, 2008). Therefore, self-efficacy can play an important role in self-regulation during the forethought phase. A high level of self-efficacy, however, does not guarantee engagement with a task. Other social cognitive constructs, such as outcome expectations, also encourage task engagement (Bandura, 1997).

In addition to initial goal setting during the forethought phase, the self-observation that occurs during the task in the performance phase is important. Athletes often evaluate their progress towards a goal, and perceived progress will then lead to changes in behaviour to increase the likelihood of goal attainment (Kane et al., 1996). For example, a runner who realises they are not making their race split times may choose to increase their pace. The runner may also use various coping strategies to cope with 


\section{SELF-REGULATION IN ENDURANCE SPORTS}

1 the sensations arising from the increase in pace. This assessment of progress may be based on

2 perceptions of physiological state (i.e., perceptions of effort and muscle pain) or in comparison with

3

4 other competitors (e.g., how competitors are performing or whether competitors are exhibiting effort and suffering) (Button, Mathieu, \& Aikin, 1996). Self-efficacy also plays a role in how athletes respond to perceived negative progress towards their goal. Notably, research showed that individuals high in self-efficacy were more likely to respond with increased effort and less negative affect, compared to low self-efficacy individuals, when they perceived themselves to be negatively progressing towards a goal during a 1500m treadmill run (Bueno, Weinberg, Fernández-Castro, \& Capdevila, 2008).

Self-efficacy is also likely to be influential during the self-reflection phase. Research has shown that both high and low self-efficacy individuals often use self-judgments, and typically attribute successful performances to factors under their own control such as their effort and ability, but they often differ in their attributions following a poor performance or when they fail to reach their goals (Chase, 2001; Feltz et al., 2008). Individuals with low self-efficacy are likely to attribute their poor performances to internal and stable factors such as a lack of ability, whereas high self-efficacy individuals are likely to attribute their poor performance to unstable factors such as their own effort or external and uncontrollable factors such as weather, other competitors, or luck (Gist \& Mitchell, 1992; Weiner, 1986). The attributions for performance are then likely to mediate the effects of that performance on future self-efficacy beliefs, in turn altering future goals and so on. To demonstrate this process, consider a cyclist who performs poorly in an important event. If the cyclist attributes this poor performance to their own ability, effort or strategy, their poor performance may negatively influence their self-efficacy. However, if they attribute their poor performance to more external uncontrollable factors such as the weather, or other competitors performing better than expected, their poor performance may not negatively impact their self-efficacy. This demonstrates the cyclical nature of self-regulation, and how self-efficacy can play a key part in it.

In these phases of self-regulation, self-efficacy helps to initiate and maintain behaviour that can guide a performer to, or away from, a goal. It has been suggested that self-efficacy is beneficial for endurance performance. For example, in observational research, self-efficacy has been associated with better performance times in iron-distance triathlon (Burke \& Jin, 1996), marathon running 


\section{SELF-REGULATION IN ENDURANCE SPORTS}

1 (Okwumabua, 1985), and cross-country running (Martin \& Gill, 1995). The majority of this research,

2 however, has focused on correlational data with limited attempts at controlling for physiological

3 differences between participants. Experimental studies that have manipulated self-efficacy (Howle et

4 al., 2016; Miller, 1993) have demonstrated that enhanced self-efficacy can lead to superior endurance

5 performance. Not all research, however, has found a consistent relationship between self-efficacy and

6 endurance performance. Martin (2002) investigated self-efficacy beliefs in wheelchair road racers and

7 found no association between self-efficacy and performance. This lack of a relationship may be related

8 to how self-efficacy was measured. Martin (2002) opted to measure self-efficacy with a self-grounded

9 perspective, by asking participants how confident they were that they could complete the race within a certain number of seconds of their goal time. Other studies (e.g. Burke \& Jin, 1996; Okwumabua, 1985), instead measured self-efficacy beliefs in regards to a descending list of possible performance times.

This highlights the need for researchers to be aware of how they are measuring self-efficacy beliefs, and how such measurement differences may influence findings (see Bandura, 2006, for a guide on development of self-efficacy scales).

As well as directly investigating self-efficacy and endurance performance, studies have investigated how self-efficacy might influence key endurance-performance mechanisms. As discussed previously, perception of effort (Marcora et al., 2008) and perceived pain (Mauger, 2014) are experienced during endurance performance and are relevant to performance. They require selfregulation for endurance athletes to maintain behaviour and progress towards their goals. When considering perception of effort, research has shown that self-efficacy can predict effort tolerance. Preexercise self-efficacy has been to found to predict variance in RPE throughout cycling tasks (McAuley \& Courneya, 1992) and predict RPE in the final minute of aerobic exercise protocols (Rudolph \& McAuley, 1996). It must be considered, however, that these two studies tested people who were not endurance athletes and, therefore, the effects of self-efficacy on perception of effort in trained endurance athletes remains unclear.

Alongside this influence on perception of effort, high levels of self-efficacy are hypothesised to improve pain tolerance (Bandura, 1989, 1997). Research examining exercise-induced pain hasshown that both experimentally-induced (Hutchinson et al., 2008; Weinberg, Gould, \& Jackson, 1979; 


\section{SELF-REGULATION IN ENDURANCE SPORTS}

1 Weinberg et al., 1981) and pre-existing self-efficacy (Baker \& Kirsch, 1991; McAuley \& Courneya,

2 1992; Weinberg et al., 1981) can influence individuals' pain tolerance. Furthermore, individuals who

3 engage in consistent endurance training have displayed higher pain thresholds and greater levels of selfefficacy in pain management than people who are not endurance athletes (Johnson, Stewart, Humphries, \& Chamove, 2012). The pain that individuals were exposed to is hypothesised to not be affected by muscular development, blood flow, and vasomotor activity (Benjamin \& Helvey, 1963), and it is therefore likely that this improved pain tolerance is caused by psychological adaptations such as changes in perceived efficacy for pain tolerance. Causality of the relationship was out of the scope of the study, but nevertheless it demonstrates the potential effects of self-efficacy on pain tolerance.

In summary, self-efficacy beliefs are likely to play a key role in each of the three phases of selfregulation. Research has consistently suggested that self-efficacy is associated with improved selfregulation in factors such as effort tolerance, pain tolerance, and overall endurance performance; the literature, however, has largely focused on correlational studies or studies that do not use trained endurance athletes.

\section{Emotion Regulation}

Endurance athletes encounter many stressors (e.g., weather, temperature, equipment) before and during events (e.g., O'Neil \& Steyn, 2007) that, depending on the athlete's appraisal of them (e.g., Martinent \& Ferrand, 2015), could have helpful or harmful consequences. Research has shown that endurance athletes do experience harmful (i.e., dysfunctional) emotional responses such as anxiety, frustration, and discouragement in response to stressors before and during performance, as well as detrimental consequences to their motivation and focus of attention (McCormick et al., 2016). Other potentially harmful consequences of emotional responses are reduced confidence and concentration, and each of these consequences have implications for performance (Lazarus, 2000; Martinent \& Ferrand, 2009; Vast, Young, \& Thomas, 2010). Nevertheless, some emotional responses are potentially helpful (i.e., functional) for athletes, such as when emotions like anger, anxiety, or joy benefit concentration, motivation, confidence, bodily states (e.g., relaxation), and adaptive behaviours (e.g., adaptive risk taking) (Martinent \& Ferrand, 2009). An important consideration - and a central concern of the field of emotion regulation (Gross, 2013) —is therefore how an athlete can cultivate emotions 


\section{SELF-REGULATION IN ENDURANCE SPORTS}

that are helpful, and manage emotions that are harmful. Performance aside, some emotions experienced before, during, and after endurance events are more pleasant than others, and the field of emotion regulation considers how pleasant emotions can be encouraged (Quoidbach, Mikolajczak, \& Gross, 2015). For example, participating in endurance events can be a source of excitement and happiness or of anger and guilt (Lahart et al., 2013; McCormick et al., 2016, 2018), impacting the quality of the event experience.

Emotion regulation refers to, "the processes by which individuals influence which emotions they have, when they have them, and how they experience and express these emotions" (Gross, 1998, p. 275). In a sport context, it is considered to mean people's automatic or deliberate use of thoughts and behaviours to influence the experience of desirable or undesirable emotions, so that they have a more pleasurable experience (hedonic motives) or improve their performance (instrumental motives) (Lane, Beedie, Jones, Uphill, \& Devonport, 2012; Uphill, McCarthy, \& Jones, 2009). Consistent with the themes of this review, emotion regulation is a process that can guide performers towards, or away from, a goal or state. A relevant theory of emotion regulation is the process model of emotion regulation (Gross, 1998, 2013, 2015). The process model proposes that people can regulate their emotions at five time points in the process of emotion generation, organising countless emotion-regulation strategies that people use into five "families" that share common qualities. People can regulate their emotions through taking actions to make it more or less likely that they will be in a situation expected to cause desired or undesired emotions (situation selection), by altering their external, physical environment (situation modification), by directing their attention (attention deployment), by changing their appraisal of an event or situation (cognitive change), or by directly regulating the experiential, behavioural, or physiological aspects of the emotion itself (response modulation).

The process model proposes that different emotion regulation strategies, and the specific tactics used to implement these strategies in a particular situation, will have different consequences for how a person feels, thinks, and acts, both momentarily and over the longer term. This is because strategies impact the process of emotion generation at different points and because strategies make different cognitive demands (Gross, 2015). For example, suppression-a response modulation strategy that involves inhibiting the outward signs of experienced inner feelings-is ineffective at reducing the 


\section{SELF-REGULATION IN ENDURANCE SPORTS}

1 experience of negatively-toned emotions and places a greater demand on finite cognitive resources than

2 re-appraisal, which is a cognitive change strategy that involves changing the way a situation is construed

3 to decrease its emotional impact (Gross, 2002) (for a critical discussion of the relationship between the points in the emotion-generation process targeted by strategies and the effects of these strategies, see Koole, van Dillen, \& Sheppes, 2011). In the endurance literature, Wagstaff (2014) demonstrated that suppressing emotions before performing (i.e., in the forethought phase) can be detrimental. Concealing feelings of disgust for three minutes before a $10 \mathrm{~km}$ cycling time trial led to endurance athletes completing the time trial slower, generating lower mean power outputs, reaching a lower maximum heart rate, and perceiving higher effort during performance. Although there is some additional research on emotion regulation within endurance sports (e.g., Beedie, Lane, \& Wilson, 2012), including experimental research that has examined the effects of emotion-regulation strategies on psychological variables and performance (Lane et al., 2016), there is currently a paucity of research examining or comparing the effects of interventions specifically informed by the process model.

Athletes use a wide variety of strategies to regulate their emotions (e.g., Nicholls et al., 2009; Stanley, Lane, Beedie, Friesen, \& Devonport, 2012), and these strategies act at different stages of the process of emotion generation (Lane et al., 2012). Applying the process model, used strategies could be expected to vary in their efficacy at controlling undesirable emotions such as anxiety, anger, or sadness (Webb, Miles, \& Sheeran, 2012), and to have consequences that may be more or less adaptive for particular situations. For example, research shows that reappraisal is generally an adaptive strategy (Gross, 2002). Nevertheless, distraction may be more adaptive than reappraisal when there is very limited time available, when an emotion is very intense, and when an athlete's ability to use cognitive resources is compromised such as when sleep deprived or when distracted by additional cognitive demands such as difficult navigation (McRae, 2016). In addition, reappraisal may be less adaptive when stressors can be controlled, compared to when they cannot (Troy, Shallcross, \& Mauss, 2013). In such situations, situation modification strategies that help an athlete to quickly and constructively deal with a stressor could be particularly helpful. For example, if-then planning (Achtziger, Gollwitzer, \& Sheeran, 2008) could be used to identify responses to stressors, and endurance athletes could visualise implementing these responses (e.g., visualising repairing a puncture) or actually practice doing them 


\section{SELF-REGULATION IN ENDURANCE SPORTS}

1 (e.g., taking goggles on and off during a swim) (McCormick et al., 2016). What makes an emotion-

2 regulation strategy particularly helpful therefore depends on the situation, as well as the characteristics

3 of the person and the goals they are pursuing (Gross, 2015). As elaborated on later (Implications for

$4 \quad$ Future Research section, Emotion regulation subsection), intervention research informed by the process

5 model could shed light on the strategies that are particularly adaptive for situations commonly

6 encountered by endurance athletes, when they have hedonic or instrumental goals for emotion

7 regulation. By doing so, this research could inform selection (i.e., in the forethought stage) and then use

8 (i.e., in the performance stage) of adaptive emotion-regulation strategies. Sport psychology practitioners

9 may also play an important role in helping endurance athletes to evaluate (i.e., in the reflection stage)

10 the utility of different emotion-regulation strategies they used and to subsequently refine them, using a

11 theoretical framework.

\section{Implications for Future Research}

We have argued that research that is informed by theories relating to self-regulation, particularly research informed by self-efficacy theory and the process model of emotion regulation, could advance understanding of endurance performance. In this section, we will focus on the third aim of the review and outline theoretically-informed suggestions for future research, focusing on the three phases of self-regulation, self-efficacy, and emotion regulation.

Three phases of self-regulation. Some research has been conducted on the forethought and performance stages, that is, on processes before and during endurance performance. For example, with consideration to the forethought stage, research has examined the effects of goal difficulty on improvements in middle-distance running times (Tenenbaum, Spence, \& Christensen, 1999), and the influence of emotion suppression on cycling performance (Wagstaff, 2014). With consideration to the performance stage, research has examined the effects of using pre-selected attentional strategies, selftalk, imagery, relaxation, and combinations of these during performance (for reviews, see Brick, MacIntyre, \& Campbell, 2014; McCormick et al., 2015). Comparatively little research has been conducted on the self-reflection stage, and the cyclical nature of self-regulation is often not considered. 


\section{SELF-REGULATION IN ENDURANCE SPORTS}

cognitive strategies and their performance, they acquire cognitive strategies through experience, and they eliminate ineffective cognitive strategies (Brick et al., 2015).

Self-efficacy. Research focusing on self-efficacy and endurance performance has demonstrated that self-efficacy is a strong predictor of performance (Burke \& Jin, 1996; Laguardia \& Labbé, 1993). Despite the value of researching the role of self-efficacy in endurance performance, we observed that research examining self-efficacy and performance in experienced athletes is scarce. Although manipulation of self-efficacy in experienced athletes can be more difficult than in novices (Feltz, Short, \& Sullivan, 2008), the use of false performance feedback (Montes, Wulf, \& Navalta, 2017; Stoate, Wulf, \& Lewthwaite, 2012) and task deception (Jones et al., 2013) can be effective in altering selfefficacy in experienced athletes. In addition, using people who are not endurance athletes as participants can make it challenging to understand how self-efficacy affects endurance performance when a participant may not perceive the various stressors that are typically experienced during endurance performance. That is, if a participant does not care for the task, this has implications for how we interpret the findings (Maddux, 1995). To clarify, participants may have external reasons for taking part in a study, such as for course credit, and the participant is therefore not necessarily autonomously motivated (see Deci \& Ryan, 2000). Moreover, they may not experience volition, and self-regulated learning may not take place.

Additionally, self-efficacy research in endurance performance is overly reliant on performance measures of self-efficacy, outcome measures of self-efficacy, or both. Although these beliefs are important, Feltz et al. (2008) cautioned against an overreliance on these because performance in sport is multifactorial. Instead, they recommended measuring self-efficacy relating to behaviours that must be carried out to achieve certain performance levels. An example is coping self-efficacy, which is an individual's belief in their own ability to cope with difficulties and engage in a variety of coping strategies (Chesney, Neilands, Chambers, Taylor, \& Folkman, 2006). Given that effective coping is a key requirement in endurance performance, research into the relationship between coping self-efficacy and endurance performance is warranted. There is also a lack of research relating to how self-efficacy may change during events. This is relevant given that self-efficacy is a dynamic construct that can change based on both perceptions of the self and the environment (Gist \& Mitchell, 1992). Although 


\section{SELF-REGULATION IN ENDURANCE SPORTS}

measuring self-efficacy during endurance performance poses practical difficulties, recent research suggests that a think-aloud protocol can be used with runners (Samson et al., 2017) and cyclists (Whitehead et al., 2017) to gain understanding of their thoughts. This may also provide further insight into the cyclical nature of self-regulation.

Emotion regulation. Research examining the effects of one specific emotion regulation strategy (cf. Wagstaff, 2014), or comparing the effects of different emotion regulation strategies, has benefited theoretical insight and practical application, and can continue to do so (Gross, 2015). These studies could shed light on the effects of emotion-regulation strategies endurance athletes use (or could use), before or while performing, on variables relevant to endurance events such as desirable and undesirable emotions, attention to task-relevant cues, decision making, perception of effort, performance, and satisfaction. Researchers are particularly encouraged to consider the goals of emotion regulation (i.e., instrumental goals relating to performance or hedonic goals relating to having a pleasurable experience) and situational factors for determining whether a strategy is adaptive. Relevant situational considerations could include controllability of the stressors, intensity of emotions, time available for emotion regulation, sleep deprivation, and having additional cognitive demands (McRae, 2016). Further, research could give particular consideration to identifying adaptive blends of strategies (i.e., using combinations involving increasing use of some strategies, and decreasing others) and sequences of strategies (e.g., using distraction to reduce an intense, harmful emotion before using reappraisal) for the particular context (Gross, 2015). Studies could also recognise the cyclical nature of self-regulation by examining the effects of emotion-regulation strategies used in specific phases of selfregulation on other phases of the self-regulation (e.g., the effects of post-performance emotion regulation on goal setting for the next event).

Experimental research. From our review, it is evident that there are challenges relating to generalisation of findings from laboratory-based research to real-world endurance performance. Although laboratory research provides experimental control, it is rare that an endurance performer will train and compete in a controlled environment. This is relevant because external stressors such as other competitors, weather, or a missed water stop, and associated emotional responses (e.g., dejection), play a role in endurance performance, and drop-out from events is common (Antonini Philippe, Rochat, 


\section{SELF-REGULATION IN ENDURANCE SPORTS}

1 Vauthier, \& Hauw, 2016; McCormick et al., 2018). Although it can be useful to isolate factors that may

2 impact endurance performance, we do not understand well enough how performance in the laboratory

3

4

5

6

7

8

9 translates to the real-world when different psychological stressors are experienced, especially when combined with physiological strain. Further, stressors could have accumulative effects. For example, discouragement by adverse weather or equipment problems could cause a lapse in concentration (Martinent \& Ferrand, 2009) that causes an athlete to become distracted from their pace or miss a turnoff from their ultramarathon route. We therefore encourage researchers to examine the effects of psychological interventions at real-life endurance events (see also Meredith, Dicks, Noel, \& Wagstaff, 2017). To date, few studies have done this (Lindsay, Maynard, \& Thomas, 2005; Sheard \& Golby, 2006), especially using a randomised, controlled experimental design (McCormick et al., 2018). Examining the effects of interventions at real-life events would also be valuable because participants are likely to be highly motivated to offer a high amount of effort, independent of whether they are in an experimental or control condition, because they care about the event that they are participating in. It is questionable whether some populations of study participants (e.g., students, colleagues, recreational exercisers who are not committed endurance athletes) are likely to offer their maximum effort in an endurance task, particularly when verbal encouragement, head-to-head competition, or other motivational methods are not employed.

Nevertheless, conducting research at real-life events poses challenges relating to attaining an adequate sample size and providing an intervention to the control group to prevent them pursuing the experimental intervention, which they may perceive as being potentially beneficial to them (McCormick et al., 2018). Suggestions are therefore offered for controlled laboratory and field research. First, researchers are encouraged to approach the research recruitment process with care. We suggest approaching local competitive and non-competitive endurance sport clubs for volunteers, rather than more convenience samples such as colleagues and students. This will allow interventions to be examined on populations of people that are more representative of the population that the intervention is intended for. It could also lead to people participating whose motivation is more self-determined. As a consequence, they may offer greater effort in each condition (Frederick-Recascino, 2002), leading to intervention effects that are more reflective of those that may be achieved at a real-life event. Future 


\section{SELF-REGULATION IN ENDURANCE SPORTS}

laboratory and field research could also examine whether certain strategies are efficacious at helping athletes to cope with stressors that are simulated under controlled conditions (for examples of the effects of interventions for coping with performing in the heat, see Barwood et al., 2008; Wallace et al., 2017). For example, researchers could examine the effects of emotion-regulation strategies used to cope with time penalties that cyclists are told occur randomly (e.g., to simulate a puncture when they are aiming to achieve a time), but that are systematically delivered. When conducting research in laboratory and field settings, researchers are encouraged to consider creating motivated performance situations, and to test the effects of interventions when athletes are performing in them. For example, to include head-tohead competition in a consistent manner, a computer-generated avatar that is an accurate (Corbett et al., 2012, 2018) or slightly superior (Williams, Jones, Sparks, Midgley, et al., 2015) representation of an earlier performance could be described as representing the performance of a competitor of similar ability. Finally, we encourage researchers to collect data post-performance, as this can provide insight into the reasons that participants give for their performance (Parry, Chinnasamy, Papadopoulou, Noakes, \& Micklewright, 2011) and that inform future efforts, which resembles the cyclical nature of the three-phase approach to self-regulation.

\section{Applied Implications}

Moving to the fourth aim, we will now provide theoretically-informed and evidence-based guidance for enhancing performance and improving the quality of experience for endurance athletes. An important consideration in endurance research is that many people participate in endurance events at sub-elite competitive and non-competitive levels, and these people are unlikely to have access to a sport psychology practitioner (e.g., McCormick et al., 2016). Nevertheless, interventions that are brief, simple, and practical can be delivered before, during, and after mass-participation events, particularly to groups of athletes. These interventions could be delivered using a variety of media such as webpages and webinars, workshops, written handouts, dinner speeches, and brief conversations with athletes at events (Meijen, Day, \& Hays, 2017). Providing support before, during, and after events fits well with the three phases of self-regulation.

Psychobiological model. The potential impact of motivational interventions is highlighted by the role of potential motivation in determining endurance performance in the psychobiological model 


\section{SELF-REGULATION IN ENDURANCE SPORTS}

1 (Marcora, 2010) and supported by research (e.g., Corbett et al., 2012; Moffatt et al., 1994; Smirmaul et

2 al., 2015; Theodorakis et al., 1998, for a review see McCormick et al., 2015). Practical motivational

3 interventions could be used to enhance performance during training and events. Competition could be

4 carefully introduced into the training environment, so that it encourages athletes to focus on perceptions

5 of competence that are self-referenced, rather than normatively-referenced (Harwood, Keegan, Smith,

6 \& Raine, 2015). For example, athletes could start training races at different moments based on their anticipated performance time, and the coach could emphasise performance time over finishing position.

8 Endurance athletes who train alone may find it motivating to use a training watch or mobile-phone application that allows them to compete against the times of other people or that delivers verbal encouragement at customised moments (Corbett et al., 2012; Moffatt et al., 1994). Furthermore, verbal encouragement could be delivered systematically during solo endurance events. For example, video screens in stadiums could encourage a crowd to cheer louder during selected moments of an attempt to break the one-hour cycling record. Moreover, motivational messages displayed on signs during massparticipation events are perceived favourably by entrants (Meijen et al., 2017). Music can also increase motivation and benefit performance (e.g., Smirmaul et al., 2015).

Three phases of self-regulation. In the forethought phase, it is recommended that athletes consider the goals they set for the training session or the race, and whether it would be appropriate to set different layers of goals (Meijen et al., 2017). A dominant focus on one outcome goal can influence an endurance athlete's affective responses during the performance phase, if they are unlikely to attain this goal (Gaudreau, Blondin, \& Lapierre, 2002). We also suggest that it may be helpful to consider ifthen planning (e.g., "If the weather is awful, then I will adjust my goal.") at this stage (Achtziger et al., 2008), which can then be applied during the performance phase. For the performance phase, motivational self-talk can be used for various purposes, such as to tolerate effort, cope with "hitting the wall" in a marathon, and enhance performance (Blanchfield et al., 2014; Schüler \& Langens, 2007; Wallace et al., 2017). Very little research has focused on the self-reflection phase. Nevertheless, endurance athletes may benefit from the process of managing crushed expectations and dealing with their race goals and performance after their event (Meijen et al., 2017). Feeling dissatisfied with performance can influence an athlete's future goal striving (Theodorakis, 1995). Therefore, we also 


\section{SELF-REGULATION IN ENDURANCE SPORTS}

1

need to return to the cyclical nature of self-regulation, and consider how this can play a role in goal pursuit. The model of action phases (Gollwitzer, 1990) outlines that there are typically four phases of goal striving (pre-decisional, post-decisional, actional, post-actional). Athletes set a goal in the predecisional phase, and then make plans for achieving this goal in the post-decisional phase. They then strive towards their goal in the actional phase. In this phase, athletes may experience barriers such as distractions and other temptations such as giving up that can threaten their goal pursuit. In the postactional phase, athletes evaluate how they have progressed towards their goal, and this phase may influence their decisions to engage in actions that can help them move towards or away from a goal. For example, as a result of the evaluation process in the post-actional phase, an athlete may decide that a longer endurance distance is not as suitable for them compared to half the distance, and adjust their goals accordingly. When practitioners are present at endurance events (Meijen et al., 2017), postperformance conversations with athletes could focus on what athletes attributed their perceived successes or failures to and explore how this may affect their motivation to pursue the activity in the future.

Self-efficacy. Self-efficacy beliefs are derived from several sources of information: past performance experiences, vicarious influences, social persuasions, and perceptions of physiological and emotional states (for a review, see Samson \& Solmon, 2011). Through these sources, athletes receive information relating to their own capabilities. This information is then appraised and processed by the athlete, alongside consideration of the task demands, giving rise to self-efficacy beliefs. Interventions that target these sources of self-efficacy in unison are likely to be more effective than those that focus on single sources (Short \& Ross-Stewart, 2009). Rather than discussing each possible intervention that increases self-efficacy (for a review, see Feltz et al., 2008), three key points that can be considered best practice for self-efficacy interventions are presented.

First, it is crucial to clarify what self-efficacy belief is being targeted. Self-efficacy beliefs are multi-dimensional (Bandura, 1997), and athletes will often vary in their self-efficacy for different behaviours, skills, or both. For example, a triathlete may have low self-efficacy for the swimming component of an event but not for the cycling and running. A self-efficacy intervention that looks to 


\section{SELF-REGULATION IN ENDURANCE SPORTS}

reinforce perceived capabilities for the event in general is likely to be less effective than one that specifically targets swimming.

Second, the experience level of the athlete should be considered. Novice, experienced, and athletes returning from injury have different self-efficacy needs that must be considered. For a novice, this is likely to be creating an initial sense of self-efficacy and subsequently increasing it gradually. This primarily occurs through gaining experience in the domain, such as through a well-structured training programme (Feltz et al., 2008). For an experienced athlete, the intervention might instead focus on reinforcing self-efficacy beliefs during difficult periods of an event rather than creating new beliefs. For an injured athlete, the intervention might sit between the two examples. Through reflection and reinforcement of what they have previously accomplished, they can regain some self-efficacy, whilst at the same time gradually increasing their own perceived capabilities through incremental training.

Third, self-efficacy interventions should not be designed to remove doubt, but rather to promote a robust sense of self-efficacy that remains during challenging and difficult situations. During the preparation phase of an event, an athlete who possesses some self-doubt over their own capabilities may be likely to prepare more thoroughly than one who possesses supreme confidence (Bandura, 1997). There is also some evidence that some self-doubt may be beneficial for exerting maximum effort during the first completion for an endurance task (Ede, Sullivan, \& Feltz, 2017).

Emotion regulation. Recreational endurance athletes, such as people participating in massparticipation events, have reported encountering stressors that could have been controlled before an event, such as running late to an event or forgetting equipment, and that led to unpleasant emotions (McCormick et al., 2016). Applying the process model, preparation may therefore be a situationselection strategy that makes it less likely that athletes will be in situations expected to cause undesirable emotions. We recommend that athletes identify and manage controllable aspects of preparation. For example, they could create a packing checklist, research likely road and car-park congestion that could make them late, and research where to park, register, find the toilets, and find pace teams. In addition, athletes could identify in advance cognitive and behavioural strategies that are likely to be helpful for coping with the stressors that are particularly likely before or during an endurance event, such as adverse weather, mechanical problems and punctures, pacing difficulties, injury, hydration, and nutrition. 


\section{SELF-REGULATION IN ENDURANCE SPORTS}

1 Thorough research of the event and speaking with people who are knowledgeable or experienced in the

2

3 event (e.g., event organisers, coaches, athletes) could be useful for identifying stressors and some potential strategies for taking control of the stressor.

Taking part in endurance events can be a source of positive emotions such as excitement and happiness before, during, and after completing the event (McCormick et al., 2018). People can use strategies from each of the five emotion-regulation families before life events, during life events, and after life events to increase their experience of positive emotions, both in the moment and longer term (Quoidbach et al., 2015). There is strong research support (see Quoidbach et al., 2015) for the following emotion-regulation strategies increasing momentary positive emotions: imagining future positive events happening (e.g., imagining completing a challenging endurance event and celebrating afterwards); holding optimistic expectations for future situations (e.g., telling yourself that you will finish an event); mindfully savouring pleasant moments as they happen (e.g., pleasant views, crossing the finish line); attributing the cause of positive events that are happening (e.g., passing the half-way point) to internal, stable, and global causes (e.g., perseverance); physically and vocally expressing positive emotions (e.g., through smiling, Brick, McElhinney, \& Metcalfe, 2018); mentally replaying pleasant events (e.g., crossing the finish line) after the event; and socially sharing past positive events (e.g., selfies after the finish line) with people who are enthusiastic and supportive. This evidence base provides a range of practical intervention options for increasing momentary positive emotions before, during, or after endurance events.

\section{Conclusion}

Psychological research on endurance performance has gathered momentum and offered evidence-based suggestions for enhancing performance in endurance events. Until recently, this research typically lacked a theoretical underpinning, and recent research has supported the psychobiological model of endurance performance. However, as most experimental research on psychological interventions for endurance performance has been conducted in the laboratory or noncompetitive field settings, the role that stressors play in endurance performance is particularly underappreciated in contemporary endurance literature. In this critical review, we have argued that selfregulation theories, particularly self-efficacy theory and the process model of emotion regulation, could 


\section{SELF-REGULATION IN ENDURANCE SPORTS}

1

also guide theoretically-informed research on endurance performance, shed additional light on how endurance performance is determined, and lead to additional understanding of how psychological interventions can be used to benefit performance and quality of experience at endurance events. We encourage researchers to consider all three phases of self-regulation (forethought, performance, and reflection) and the cyclical nature of self-regulation, to study (or simulate) performance at real-life endurance events, and to choose people who participate in events as participants in research.

\section{References}

Achtziger, A., Gollwitzer, P. M., \& Sheeran, P. (2008). Implementation intentions and shielding goal striving from unwanted thoughts and feelings. Personality and Social Psychology Bulletin, 34, 381-393. https://doi.org/10.1177/0146167207311201

Amann, M., \& Secher, N. H. (2010). Rebuttal from Amann and Secher. Journal of Applied Physiology, 108, 456-457. https://doi.org/10.1152/japplphysiol.00976.2009b

Antonini Philippe, R., Rochat, N., Vauthier, M., \& Hauw, D. (2016). The story of withdrawals during an ultra-trail running race: A qualitative investigation of runners' courses of experience. The Sport Psychologist, 30, 361-375. https://doi.org/10.1123/tsp.2016-0039

Astokorki, A. H. Y., \& Mauger, A. R. (2017). Tolerance of exercise-induced pain at a fixed rating of perceived exertion predicts time trial cycling performance. Scandinavian Journal of Medicine \& Science in Sports, 27, 309-317. https://doi.org/10.1111/sms.12659

Baker, S. L., \& Kirsch, I. (1991). Cognitive mediators of pain perception and tolerance. Journal of Personality and Social Psychology, 61, 504-510. https://doi.org/10.1037/0022-3514.61.3.504

Bandura, A. (1989). Human agency in social cognitive theory. The American Psychologist, 44, 11751184. https://doi.org/10.1037/0003-066x.44.9.1175

Bandura, A. (1997). Self-efficacy: The exercise of control. New York, NY: Freeman.

Bandura, A. (2006). Guide for constructing self-efficacy scales. In F. Pajares \& T. Urdan (Eds.), Selfefficacy beliefs of adolescents (pp. 307-337). Greenwich, CT: Information Age.

Barwood, M. J., Corbett, J., Wagstaff, C. R. D., McVeigh, D., \& Thelwell, R. C. (2015). Improvement of 10-km time-trial cycling with motivational self-talk compared with neutral self-talk. International Journal of Sports Physiology and Performance, 10, 166-171. 


\section{SELF-REGULATION IN ENDURANCE SPORTS}

https://doi.org/10.1123/ijspp.2014-0059

Barwood, M. J., Thelwell, R. C., \& Tipton, M. J. (2008). Psychological skills training improves exercise performance in the heat. Medicine \& Science in Sports \& Exercise, 40, 387-396. https://doi.org/10.1249/mss.0b013e31815adf31

Beedie, C. J., Lane, A. M., \& Wilson, M. G. (2012). A possible role for emotion and emotion regulation in physiological responses to false performance feedback in 10 mile laboratory cycling. Applied Psychophysiology Biofeedback, 37, 269-277. https://doi.org/10.1007/s10484012-9200-7

Benjamin, F. B., \& Helvey, W. M. (1963). Iontophoresis of potassium for experimental determination of pain endurance in man. Proceedings of the Society for Experimental Biology and Medicine, 113, 566-568. https://doi.org/10.3181/00379727-113-28427

Blanchfield, A. W., Hardy, J., de Morree, H. M., Staiano, W., \& Marcora, S. M. (2014). Talking yourself out of exhaustion: The effects of self-talk on endurance performance. Medicine \& Science in Sports \& Exercise, 46, 998-1007. https://doi.org/10.1249/MSS.0000000000000184

Boekaerts, M. (2010). Motivation and self-regulation: Two close friends. In T. C. Urdan \& S. A. Karabenick (Eds.), In The decade ahead: Applications and contexts of motivation and achievement, Volume 16B (pp. 69-108). Bingley, England: Emerald.

Boekaerts, M., Pintrich, P. R., \& Zeider, M. (Eds.). (2000). Handbook of self-regulation. San Diego, CA: Elsevier Academic Press.

Brehm, J. W., \& Self, E. A. (1989). The intensity of motivation. Annual Review of Psychology, 40, 109-131. https://doi.org/10.1146/annurev.ps.40.020189.000545

Brick, N. E., MacIntyre, T. E., \& Campbell, M. J. (2016). Thinking and action: A cognitive perspective on self-regulation during endurance performance. Frontiers in Physiology, 7, 159. https://doi.org/10.3389/fphys.2016.00159

Brick, N. E., McElhinney, M. J., \& Metcalfe, R. S. (2018). The effects of facial expression and relaxation cues on movement economy, physiological, and perceptual responses during running. Psychology of Sport and Exercise, 34, 20-28. https://doi.org/10.1016/j.psychsport.2017.09.009

Brick, N., MacIntyre, T., \& Campbell, M. (2014). Attentional focus in endurance activity: New 


\section{SELF-REGULATION IN ENDURANCE SPORTS}

paradigms and future directions. International Review of Sport and Exercise Psychology, 7, 106-134. https://doi.org/10.1080/1750984X.2014.885554

Brick, N., MacIntyre, T., \& Campbell, M. (2015). Metacognitive processes in the self-regulation of performance in elite endurance runners. Psychology of Sport and Exercise, 19, 1-9. https://doi.org/10.1016/j.psychsport.2015.02.003

Bueno, J., Weinberg, R. S., Fernández-Castro, J., \& Capdevila, L. (2008). Emotional and motivational mechanisms mediating the influence of goal setting on endurance athletes' performance. Psychology of Sport and Exercise, 9, 786-799. https://doi.org/10.1016/j.psychsport.2007.11.003

Burke, S. T., \& Jin, P. (1996). Predicting performance from a triathlon event. Journal of Sport Behavior, 19, 272-287.

Burnley, M., \& Jones, A. M. (2007). Oxygen uptake kinetics as a determinant of sports performance. European Journal of Sport Science, 7, 63-79. https://doi.org/10.1080/17461390701456148

Button, S. B., Mathieu, J. E., \& Aikin, K. J. (1996). An examination of the relative impact of assigned goals and self-efficacy on personal goals and performance over time. Journal of Applied Social Psychology, 26, 1084-1103. https://doi.org/10.1111/j.1559-1816.1996.tb01126.x

Carver, C. S., \& Scheier, M. F. (2009). Action, affect, multitasking, and layers of control. In J. P. Forgas, R. F. Baumeister, \& D. M. Tice (Eds.), Psychology of self-regulation: Cognitive, affective, and motivational Processes (pp. 109-126). New York, NY: Psychology Press.

Chase, M. A. (2001). Children's self-efficacy, motivational intentions, and attributions in physical education and sport. Research Quarterly for Exercise and Sport, 72, 47-54. https://doi.org/10.1080/02701367.2001.10608931

Chesney, M. A., Neilands, T. B., Chambers, D. B., Taylor, J. M., \& Folkman, S. (2006). A validity and reliability study of the coping self-efficacy scale. British Journal of Health Psychology, 11, 421-437. https://doi.org/10.1348/135910705X53155

Christensen, D. A., Brewer, B. W., \& Hutchinson, J. C. (2015). In-task assessment of psychological changes during an ultramarathon race. Wilderness \& Environmental Medicine, 26(4), e4. https://doi.org/10.1016/j.wem.2015.03.013

Clancy, R. B., Herring, M. P., MacIntyre, T. E., \& Campbell, M. J. (2016). A review of competitive 


\section{SELF-REGULATION IN ENDURANCE SPORTS}

sport motivation research. Psychology of Sport and Exercise, 27, 232-242. https://doi.org/10.1016/j.psychsport.2016.09.003

Cleary, T. J., \& Zimmerman, B. J. (2001). Self-regulation differences during athletic practice by experts, non-experts, and novices. Journal of Applied Sport Psychology, 13, 185-206. https://doi.org/10.1080/104132001753149883

Cleary, T. J., Zimmerman, B. J., \& Keating, T. (2006). Training physical education students to selfregulate during basketball free throw practice. Research Quarterly for Exercise and Sport, 77, 251-262. https://doi.org/10.1080/02701367.2006.10599358

Corbett, J., Barwood, M. J., Ouzounoglou, A., Thelwell, R., \& Dicks, M. (2012). Influence of competition on performance and pacing during cycling exercise. Medicine \& Science in Sports \& Exercise, 44, 509-515. https://doi.org/10.1249/MSS.0b013e31823378b1

Corbett, J., White, D. K., Barwood, M. J., Wagstaff, C. R. D., Tipton, M. J., McMorris, T., \& Costello, J. T. (2018). The effect of head-to-head competition on behavioural thermoregulation, thermophysiological strain and performance during exercise in the heat. Sports Medicine, 48, 1269-1279. https://doi.org/10.1007/s40279-017-0816-x

Davies, M. J., Clark, B., Welvaert, M., Skorski, S., Garvican-Lewis, L. A., Saunders, P., \& Thompson, K. G. (2016). Effect of environmental and feedback interventions on pacing profiles in cycling: A meta-analysis. Frontiers in Physiology, 7, 591. https://doi.org/10.3389/fphys.2016.00591

Deci, E. L., \& Ryan, R. M. (2000). The "what" and "why" of goal pursuits: Human needs and the self-determination of behavior. Psychological Inquiry, 11, 227-268. https://doi.org/10.1207/S15327965PLI1104_01

Dinsmore, D. L., Alexander, P. A., \& Loughlin, S. M. (2008). Focusing the conceptual lens on metacognition, self-regulation, and self-regulated learning. Educational Psychology Review, 20, 391-409. https://doi.org/10.1007/s10648-008-9083-6

Donohue, B., Miller, A., Beisecker, M., Houser, D., Valdez, R., Tiller, S., \& Taymar, T. (2006). Effects of brief yoga exercises and motivational preparatory interventions in distance runners: Results of a controlled trial. British Journal of Sports Medicine, 40, 60-63. 


\section{SELF-REGULATION IN ENDURANCE SPORTS}

https://doi.org/10.1136/bjsm.2005.020024

Ede, A., Sullivan, P. J., \& Feltz, D. L. (2017). Self-doubt: Uncertainty as a motivating factor on effort in an exercise endurance task. Psychology of Sport and Exercise, 28, 31-36. https://doi.org/10.1016/j.psychsport.2016.10.002

Edwards, A. M., \& Polman, R. C. J. (2013). Pacing and awareness: Brain regulation of physical activity. Sports Medicine, 43, 1057-1064. https://doi.org/10.1007/s40279-013-0091-4

Ekkekakis, P. (2012). Affect, mood, and emotion. In G. Tenenbaum, R. C. Eklund, \& A. Kamata (Eds.), Measurement in sport and exercise psychology (pp. 321-332). Champaign, IL: Human Kinetics.

Ekkekakis, P., Hargreaves, E. A., \& Parfitt, G. (2013). Invited Guest Editorial: Envisioning the next fifty years of research on the exercise-affect relationship. Psychology of Sport and Exercise, 14, 751-758. https://doi.org/10.1016/j.psychsport.2013.04.007

Ekkekakis, P., Parfitt, G., \& Petruzzello, S. J. (2011). The pleasure and displeasure people feel when they exercise at different intensities: Decennial update and progress towards a tripartite rationale for exercise intensity prescription. Sports Medicine, 41, 641-671. https://doi.org/10.2165/11590680-000000000-00000

Elferink-Gemser, M. T., \& Hettinga, F. J. (2017). Pacing and self-regulation: Important skills for talent development in endurance sports. International Journal of Sports Physiology and Performance, 12, 831-835. https://doi.org/10.1123/ijspp.2017-0080

Feltz, D. L., Short, S. E., \& Sullivan, P. J. (2008). Self-efficacy in sport. Champaign, IL: Human Kinetics.

Frederick-Recascino, C. M. (2002). Self-determination theory and participation motivation research in the sport and exercise domain. In E. L. Deci \& R. M. Ryan (Eds.), Handbook of selfdetermination research (pp. 277-294). Rochester, NY: University of Rochester Press.

Gastin, P. B. (2001). Energy system interaction and relative contribution during maximal exercise. Sports Medicine, 31, 725-741. https://doi.org/10.2165/00007256-200131100-00003

Gaudreau, P., Blondin, J.-P., \& Lapierre, A.-M. (2002). Athletes' coping during a competition: relationship of coping strategies with positive affect, negative affect, and performance-goal 
SELF-REGULATION IN ENDURANCE SPORTS

discrepancy. Psychology of Sport and Exercise, 3, 125-150. https://doi.org/10.1016/S14690292(01)00015-2

Gist, M. E., \& Mitchell, T. R. (1992). Self-efficacy: A theoretical analysis of its determinants and malleability. Academy of Management Review, 17, 183-211. https://doi.org/10.2307/258770

Gollwitzer, P. M. (1990). Action phases and mind-sets. In E. T. Higgins \& R. M. Sorrentino (Eds.), Handbook of motivation and cognition: Foundations of social behavior (Volume 2) (pp. 53-92). New York, NY: Guildford Press.

Gross, J. J. (1998). The emerging field of emotion regulation: An integrative review. Review of General Psychology, 2, 271-299. https://doi.org/10.1037/1089-2680.2.3.271

Gross, J. J. (2002). Emotion regulation: Affective, cognitive, and social consequences. Psychophysiology, 39, 281-291. https://doi.org/10.1017.S0048577201393198

Gross, J. J. (2013). Emotion regulation: Taking stock and moving forward. Emotion, 13, 359-365. https://doi.org/10.1037/a0032135

Gross, J. J. (2015). The extended process model of emotion regulation: Elaborations, applications, and future directions. Psychological Inquiry, 26, 130-137. https://doi.org/10.1080/1047840X.2015.989751

Hardy, C. J., \& Rejeski, W. J. (1989). Not what, but how one feels: The measurement of affect during exercise. Journal of Sport \& Exercise Psychology, 11, 304-317. https://doi.org/10.1123/jsep.11.3.304

Harwood, C. G., Keegan, R. J., Smith, J. M. J., \& Raine, A. S. (2015). A systematic review of the intrapersonal correlates of motivational climate perceptions in sport and physical activity. Psychology of Sport and Exercise, 18, 9-25. https://doi.org/10.1016/j.psychsport.2014.11.005

Hettinga, F. J., Konings, M. J., \& Pepping, G.-J. (2017). The science of racing against opponents: Affordance competition and the regulation of exercise intensity in head-to-head competition. Frontiers in Physiology, 8, 118. https://doi.org/10.3389/fphys.2017.00118

Hollander, D. B., \& Acevedo, E. O. (2000). Successful English Channel swimming: The peak experience. The Sport Psychologist, 14, 1-16. https://doi.org/10.1123/tsp.14.1.1

Holt, N. L., Lee, H., Kim, Y., \& Klein, K. (2014). Exploring experiences of running an ultramarathon. 


\section{SELF-REGULATION IN ENDURANCE SPORTS}

The Sport Psychologist, 28, 22-35. https://doi.org/10.1123/tsp.2013-0008

Howle, T. C., Dimmock, J. A., \& Jackson, B. (2016). Relations between self-efficacy beliefs, selfpresentation motives, personal task goals, and performance on endurance-based physical activity tasks. Psychology of Sport and Exercise, 22, 149-159. https://doi.org/10.1016/j.psychsport.2015.06.010

Hutchinson, J. C., Sherman, T., Martinovic, N., \& Tenenbaum, G. (2008). The effect of manipulated self-efficacy on perceived and sustained effort. Journal of Applied Sport Psychology, 20, 457472. https://doi.org/10.1080/10413200802351151

Inzlicht, M., \& Marcora, S. M. (2016). The central governor model of exercise regulation teaches us precious little about the nature of mental fatigue and self-control failure. Frontiers in Psychology, 7, 656. https://doi.org/10.3389/fpsyg.2016.00656

Johnson, M. H., Stewart, J., Humphries, S. A., \& Chamove, A. S. (2012). Marathon runners' reaction to potassium iontophoretic experimental pain: pain tolerance, Pain threshold, coping and selfefficacy. European Journal of Pain, 16, 767-774. https://doi.org/10.1002/j.15322149.2011.00059.x

Jones, A. M., Vanhatalo, A., Burnley, M., Morton, R. H., \& Poole, D. C. (2010). Critical power: Implications for determination of VO2max and exercise tolerance. Medicine \& Science in Sports \& Exercise, 42, 1876-1890. https://doi.org/10.1249/MSS.0b013e3181d9cf7f

Jones, H. S., Williams, E. L., Bridge, C. A., Marchant, D., Midgley, A. W., Micklewright, D., \& McNaughton, L. R. (2013). Physiological and psychological effects of deception on pacing strategy and performance: A review. Sports Medicine, 43, 1243-1257. https://doi.org/10.1007/s40279-013-0094-1

Jones, H. S., Williams, E. L., Marchant, D., Sparks, S. A., Midgley, A. W., Bridge, C. A., \& McNaughton, L. (2014). Distance-dependent association of affect with pacing strategy in cycling time trials. Medicine \& Science in Sports \& Exercise, 47, 825-832. https://doi.org/10.1249/MSS.0000000000000475

Joyner, M. J., \& Coyle, E. F. (2008). Endurance exercise performance: the physiology of champions. The Journal of Physiology, 586, 35-44. https://doi.org/10.1113/jphysiol.2007.143834 


\section{SELF-REGULATION IN ENDURANCE SPORTS}

Jung, C., Ferrari, M., Goebel, B., \& Figulla, H. R. (2009). The patient's motivation during bicycle stress ECG test is dependent on the investigator's sex in male patients. International Journal of Cardiology, 136, 348-351. https://doi.org/10.1016/j.ijcard.2008.04.074

Kane, T. D., Marks, M. A., Zaccaro, S. J., \& Blair, V. (1996). Self-efficacy, personal goals, and wrestlers' self-regulation. Journal of Sport \& Exercise Psychology, 18, 36-48. https://doi.org/10.1123/jsep.18.1.36

King, M. F., \& Bruner, G. C. (2000). Social desirability bias: A neglected aspect of validity testing. Psychology and Marketing, 17, 79-103. https://doi.org/10.1002/(SICI)15206793(200002)17:2<79::AID-MAR2>3.0.CO;2-0

Kitsantas, A., \& Zimmerman, B. J. (2002). Comparing self-regulatory processes among novice, nonexpert, and expert volleyball players: A microanalytic study. Journal of Applied Sport Psychology, 14, 91-105. https://doi.org/10.1080/10413200252907761

Konings, M. J., Schoenmakers, P. P. J. M., Walker, A. J., \& Hettinga, F. J. (2016). The behavior of an opponent alters pacing decisions in 4-km cycling time trials. Physiology and Behavior, 158, 1-5. https://doi.org/10.1016/j.physbeh.2016.02.023

Koole, S. L., van Dillen, L. F., \& Sheppes, G. (2011). The self-regulation of emotion. In K. D. Vohs \& R. F. Baumeister (Eds.), Handbook of self-regulation: Research, theory, and applications (pp. 22-40). New York, NY: Guildford Press.

Kress, J. L., \& Statler, T. (2007). A naturalistic investigation of former Olympic cyclists' cognitive strategies for coping with exertion pain during performance. Journal of Sport Behavior, 30, 428452.

Kuhl, J. (2000). A functional-design approach to motivation and self-regulation: The dynamics of personality systems interactions. In M. Boekaerts, P. R. Pintrich, \& M. Zeidner (Eds.), Handbook of self-regulation (pp. 111-169). San Diego, CA: Academic Press.

Laguardia, R., \& Labbé, E. E. (1993). Self-efficacy and anxiety and their relationship to training and race performance. Perceptual and Motor Skills, 77, 27-34. https://doi.org/10.2466/pms.1993.77.1.27

Lahart, I. M., Lane, A. M., Hulton, A., Williams, K., Godfrey, R., Pedlar, C., ... Whyte, G. P. (2013). 


\section{SELF-REGULATION IN ENDURANCE SPORTS}

Challenges in maintaining emotion regulation in a sleep and energy deprived state induced by the 4800km ultra-endurance bicycle race; the Race Across AMerica (RAAM). Journal of Sports Science and Medicine, 12, 481-488.

Lane, A. [Andrew] M., Beedie, C. J., Jones, M. V, Uphill, M., \& Devonport, T. J. (2012). The BASES Expert Statement on emotion regulation in sport. Journal of Sports Sciences, 30, 1189-1195. http://doi.org/10.1080/02640414.2012.693621

Lane, A. [Andrew] M., Devonport, T. J., Friesen, A. P., Beedie, C. J., Fullerton, C. L., \& Stanley, D. M. (2016). How should I regulate my emotions if I want to run faster? European Journal of Sport Science, 16, 465-472. http://doi.org/10.1080/17461391.2015.1080305

Lane, A. [Aoife], Murphy, N. M., \& Bauman, A. (2008). The impact of participation in the Flora Women's Mini Marathon on physical activity behaviour in women. Research Report 1. Ireland: Centre for Health Behaviour Research, Department of Health Sport and Exercise Sciences, Waterford Institute of Technology and Irish Sports Council.

Lazarus, R. S. (2000). How emotions influence performance in competitive sports. The Sport Psychologist, 14, 229-252. https://doi.org/10.1123/tsp.14.3.229

Lindsay, P., Maynard, I., \& Thomas, O. (2005). Effects of hypnosis on flow states and cycling performance. The Sport Psychologist, 19, 164-177. https://doi.org/10.1123/tsp.19.2.164

Locke, E. A., \& Latham, G. P. (1985). The application of goal setting to sports. Journal of Sport \& Exercise Psychology, 7, 205-222. https://doi.org/10.1123/jsp.7.3.205

Locke, E. A., \& Latham, G. P. (2002). Building a practically useful theory of goal setting and task motivation: A 35-year odyssey. American Psychologist, 57, 705-717. https://doi.org/10.1037/0003-066X.57.9.705

Maddux, J. E. (1995). Self-efficacy theory: An introduction. In J. E. Maddux (Ed.), Self-efficacy, adaptation, and adjustment (pp. 3-33). New York, NY: Springer.

Mallett, C. J., \& Hanrahan, S. J. (2004). Elite athletes: why does the "fire" burn so brightly? Psychology of Sport and Exercise, 5, 183-200. https://doi.org/10.1016/S1469-0292(02)00043-2

Marcora, S. (2009). Perception of effort during exercise is independent of afferent feedback from skeletal muscles, heart, and lungs. Journal of Applied Physiology, 106, 2060-2062. 


\section{SELF-REGULATION IN ENDURANCE SPORTS}

https://doi.org/10.1152/japplphysiol.90378.2008

Marcora, S. (2010). Counterpoint: Afferent feedback from fatigued locomotor muscles is not an important determinant of endurance exercise performance. Journal of Applied Physiology, 108, 454-456. https://doi.org/10.1152/japplphysiol.00976.2009a

Marcora, S. (2015, December). The limit to endurance performance: Mind over muscle? Paper presented at the British Psychological Society Division of Sport and Exercise Psychology Conference, Cardiff, Wales.

Marcora, S. M., \& Bosio, A. (2007). Effect of exercise-induced muscle damage on endurance running performance in humans. Scandinavian Journal of Medicine \& Science in Sports, 17, 662-671. https://doi.org/10.1111/j.1600-0838.2006.00627.x

Marcora, S. M., Bosio, A., \& de Morree, H. M. (2008). Locomotor muscle fatigue increases cardiorespiratory responses and reduces performance during intense cycling exercise independently from metabolic stress. American Journal of Physiology - Regulatory, Integrative and Comparative Physiology, 294, R874-R883. https://doi.org/10.1152/ajpregu.00678.2007

Martin, J. J. (2002). Training and performance self-efficacy, affect, and performance in wheelchair road racers. The Sport Psychologist, 16, 384-395. https://doi.org/10.1123/tsp.16.4.384

Martin, J. J., \& Gill, D. L. (1995). The relationships of competitive orientations and self-efficacy to goal importance, thoughts, and performance in high school distance runners. Journal of Applied Sport Psychology, 7, 50-62. https://doi.org/10.1080/10413209508406300

Martinent, G., \& Ferrand, C. (2009). A naturalistic study of the directional interpretation process of discrete emotions during high-stakes table tennis matches. Journal of Sport \& Exercise Psychology, 31, 318-336. https://doi.org/10.1123/jsep.31.3.318

Martinent, G., \& Ferrand, C. (2015). A field study of discrete emotions: Athletes' cognitive appraisals during competition. Research Quarterly for Exercise and Sport, 86, 51-62. https://doi.org/10.1080/02701367.2014.975176

Mauger, A. R. (2014). Factors affecting the regulation of pacing: current perspectives. Open Access Journal of Sports Medicine, 5, 209-214. https://doi.org/10.2147/OAJSM.S38599

Mauger, A. R., Jones, A. M., \& Williams, C. A. (2010). Influence of acetaminophen on performance 


\section{SELF-REGULATION IN ENDURANCE SPORTS}

during time trial cycling. Journal of Applied Physiology, 108, 98-104. https://doi.org/10.1152/japplphysiol.00761.2009

McAuley, E., \& Courneya, K. S. (1992). Self-efficacy relationships with affective and exertion responses to exercise. Journal of Applied Social Psychology, 22, 312-326. https://doi.org/10.1111/j.1559-1816.1992.tb01542.x

McCormick, A., Meijen, C., \& Marcora, S. (2015). Psychological determinants of whole-body endurance performance. Sports Medicine, 45, 997-1015. https://doi.org/10.1007/s40279-0150319-6

McCormick, A., Meijen, C., \& Marcora, S. (2016). Psychological demands experienced by recreational endurance athletes. International Journal of Sport and Exercise Psychology. https://doi.org/10.1080/1612197X.2016.1256341

McCormick, A., Meijen, C., \& Marcora, S. (2018). Effects of a motivational self-talk intervention for endurance athletes completing an ultramarathon. The Sport Psychologist, 32, 42-50. https://doi.org/10.1123/tsp.2017-0018

McRae, K. (2016). Cognitive emotion regulation: a review of theory and scientific findings. Current Opinion in Behavioral Sciences, 10, 119-124. https://doi.org/10.1016/j.cobeha.2016.06.004 Meijen, C., Day, C., \& Hays, K. F. (2017). Running a psyching team: Providing mental support at long-distance running events. Journal of Sport Psychology in Action, 8, 12-22. https://doi.org/10.1080/21520704.2016.1205697

Meredith, S. J., Dicks, M., Noel, B., \& Wagstaff, C. R. D. (2017). A review of behavioural measures and research methodology in sport and exercise psychology. International Review of Sport and Exercise Psychology. https://doi.org/10.1080/1750984X.2017.1286513

Michie, S., \& Prestwich, A. (2010). Are interventions theory-based? Development of a theory coding scheme. Health Psychology, 29, 1-8. https://doi.org/10.1037/a0016939

Micklewright, D., Kegerreis, S., Raglin, J., \& Hettinga, F. (2017). Will the conscious-subconscious pacing quagmire help elucidate the mechanisms of self-paced exercise? New opportunities in dual process theory and process tracing methods. Sports Medicine, 47, 1231-1239. https://doi.org/10.1007/s40279-016-0642-6 


\section{SELF-REGULATION IN ENDURANCE SPORTS}

Micklewright, D., \& Parry, D. (2010). The central governor model cannot be adequately tested by observing its components in isolation. Sports Medicine, 40, 91-94. https://doi.org/10.2165/11531360-000000000-00000

Miller, M. (1993). Efficacy strength and performance in competitive swimmers of different skill levels. International Journal of Sport Psychology, 24, 284-296.

Miller, P. H., Kessel, F. S., \& Flavell, J. H. (1970). Thinking about people thinking about people thinking about...: A study of social cognitive development. Child Development, 41, 613-623.

Moffatt, R. J., Chitwood, L. F., \& Biggerstaff, K. D. (1994). The influence of verbal encouragement during assessment of maximal oxygen uptake. The Journal of Sports Medicine and Physical Fitness, 34, 45-49.

Montes, J., Wulf, G., \& Navalta, J. W. (2017). Maximal aerobic capacity can be increased by enhancing performers' expectancies. The Journal of Sports Medicine and Physical Fitness. https://doi.org/10.23736/S0022-4707.17.07254-1

Nicholls, A. R., Levy, A. R., Grice, A., \& Polman, R. C. J. (2009). Stress appraisals, coping, and coping effectiveness among international cross-country runners during training and competition. European Journal of Sport Science, 9, 285-293. https://doi.org/10.1080/17461390902836049

Noakes, T. D. (2012). Fatigue is a brain-derived emotion that regulates the exercise behavior to ensure the protection of whole body homeostasis. Frontiers in Physiology, 3, 82 . https://doi.org/10.3389/fphys.2012.00082

Noble, B. J., \& Noble, J. M. (2000). Perception of effort during endurance training and performance. In R. J. Shephard \& P.-O. Åstrand (Eds.), Endurance in sport (2nd ed., pp. 374-394). Oxford, England: Blackwell Science.

O’Neil, J. W., \& Steyn, B. J. M. (2007). Strategies used by South African non-elite athletes to cope with the environmental stressors associated with endurance events. South African Journal for Research in Sport, Physical Education and Recreation, 29, 99-107.

Okwumabua, T. M. (1985). Psychological and physical contributions to marathon performance: An exploratory investigation. Journal of Sport Behavior, 8, 163-171.

Pageaux, B. (2016). Perception of effort in Exercise Science: Definition, measurement and 


\section{SELF-REGULATION IN ENDURANCE SPORTS}

perspectives. European Journal of Sport Science, 16, 885-894. https://doi.org/10.1080/17461391.2016.1188992

Parry, D., Chinnasamy, C., Papadopoulou, E., Noakes, T., \& Micklewright, D. (2011). Cognition and performance: anxiety, mood and perceived exertion among Ironman triathletes. British Journal of Sports Medicine, 45, 1088-1094. https://doi.org/10.1136/bjsm.2010.072637

Quoidbach, J., Mikolajczak, M., \& Gross, J. J. (2015). Positive interventions: An emotion regulation perspective. Psychological Bulletin, 141, 655-693. https://doi.org/10.1037/a0038648

Renfree, A., Carmo, E. C. do, Martin, L., \& Peters, D. M. (2015). The influence of collective behavior on pacing in endurance competitions. Frontiers in Physiology, 6, 373. https://doi.org/10.3389/fphys.2015.00373

Renfree, A., Martin, L., Micklewright, D., \& St Clair Gibson, A. (2014). Application of decisionmaking theory to the regulation of muscular work rate during self-paced competitive endurance activity. Sports Medicine, 44, 147-158. https://doi.org/10.1007/s40279-013-0107-0

Richter, M., Gendolla, G. H. E., \& Wright, R. A. (2016). Three decades of research on motivational intensity theory: What we have learned about effort and what we still don't know. Advances in Motivation Science, 3, 149-186. https://doi.org/10.1016/bs.adms.2016.02.001

Samson, A., Simpson, D., Kamphoff, C., \& Langlier, A. (2017). Think aloud: An examination of distance runners' thought processes. International Journal of Sport and Exercise Psychology, 15, 176-189. https://doi.org/10.1080/1612197X.2015.1069877

Samson, A., \& Solmon, M. (2011). Examining the sources of self-efficacy for physical activity within the sport and exercise domains. International Review of Sport and Exercise Psychology, 4, 7089. https://doi.org/10.1080/1750984X.2011.564643

Sarkar, M., \& Fletcher, D. (2014). Psychological resilience in sport performers: a review of stressors and protective factors. Journal of Sports Sciences, 32, 1419-1434. https://doi.org/10.1080/02640414.2014.901551

Scholz, U., Nagy, G., Schüz, B., \& Ziegelmann, J. P. (2008). The role of motivational and volitional factors for self-regulated running training: associations on the between- and within- person level. The British Journal of Social Psychology, 47, 421-439. 


\section{SELF-REGULATION IN ENDURANCE SPORTS}

https://doi.org/10.1348/014466607X266606

Schüler, J., \& Langens, T. A. (2007). Psychological crisis in a marathon and the buffering effects of self-verbalizations. Journal of Applied Social Psychology, 37, 2319-2344. https://doi.org/10.1111/j.1559-1816.2007.00260.x

Schumacher, J. M., Becker, A. J., \& Wiersma, L. D. (2016). Forging ahead: An examination of the experiences and coping mechanisms of channel swimmers. The Sport Psychologist, 30, 327338. https://doi.org/10.1123/tsp.2015-0137

Sheard, M., \& Golby, J. (2006). Effect of a psychological skills training program on swimming performance and positive psychological development. International Journal of Sport and Exercise Psychology, 4, 149-169. https://doi.org/10.1080/1612197X.2006.9671790

Shephard, R. J. (2009). Is it time to retire the "Central Governor"? Sports Medicine, 39, 709-721. https://doi.org/10.2165/11315130-000000000-00000

Short, S., \& Ross-Stewart, L. (2009). A review of self-efficacy based interventions. In S. D. Mellalieu \& S. Hanton (Eds.), Advances in applied sport psychology (pp. 221-280). Abingdon, England: Routledge.

Simpson, D., Post, P. G., Young, G., \& Jensen, P. R. (2014). "It's not about taking the easy road": The experiences of ultramarathon runners. The Sport Psychologist, 28, 176-185. https://doi.org/10.1123/tsp.2013-0064

Smirmaul, B. P. C., dos Santos, R. V, \& da Silva Neto, L. V. (2015). Pre-task music improves swimming performance. The Journal of Sports Medicine and Physical Fitness, 55, 1445-1451.

Smits, B. L. M., Pepping, G. J., \& Hettinga, F. J. (2014). Pacing and decision making in sport and exercise: The roles of perception and action in the regulation of exercise intensity. Sports Medicine, 44, 763-775. https://doi.org/10.1007/s40279-014-0163-0

St Clair Gibson, A., Swart, J., \& Tucker, R. (2018). The interaction of psychological and physiological homeostatic drives and role of general control principles in the regulation of physiological systems, exercise and the fatigue process - The Integrative Governor theory. European Journal of Sport Science, 18, 25-36. https://doi.org/10.1080/17461391.2017.1321688

Stanley, D. M., Lane, A. M., Beedie, C. J., Friesen, A. P., \& Devonport, T. J. (2012). Emotion 


\section{SELF-REGULATION IN ENDURANCE SPORTS}

regulation strategies used in the hour before running. International Journal of Sport and Exercise Psychology, 10, 159-171. https://doi.org/10.1080/1612197X.2012.671910

Stoate, I., Wulf, G., \& Lewthwaite, R. (2012). Enhanced expectancies improve movement efficiency in runners. Journal of Sports Sciences, 30, 815-823. https://doi.org/10.1080/02640414.2012.671533

Taylor, J. (1995). A conceptual model for integrating athletes' needs and sport demands in the development of competitive mental preparation strategies. The Sport Psychologist, 9, 339-357. https://doi.org/10.1123/tsp.9.3.339

Tenenbaum, G., Spence, R., \& Christensen, S. (1999). The effect of goal difficulty and goal orientation on running performance in young female athletes. Australian Journal of Psychology, 51, 6-11. https://doi.org/10.1080/00049539908255328

Theodorakis, Y. (1995). Effects of self-efficacy, satisfaction, and personal goals on swimming performance. The Sport Psychologist, 9, 245-253. https://doi.org/10.1123/tsp.9.3.245

Theodorakis, Y., Laparidis, K., \& Kioumourtzoglou, E. (1998). Combined effects of goal setting and performance feedback on performance and physiological response on a maximum effort task. Perceptual and Motor Skills, 86, 1035-1041. https://doi.org/10.2466/pms.1998.86.3.1035

Troy, A. S., Shallcross, A. J., \& Mauss, I. B. (2013). A person-by-situation approach to emotion regulation: Cognitive reappraisal can either help or hurt, depending on the context. Psychological Science, 24, 2505-2514. https://doi.org/10.1177/0956797613496434

Tucker, R. (2009). The anticipatory regulation of performance: the physiological basis for pacing strategies and the development of a perception-based model for exercise performance. British Journal of Sports Medicine, 43, 392-400. https://doi.org/10.1136/bjsm.2008.050799

Uphill, M. A., \& Jones, M. V. (2007). Antecedents of emotions in elite athletes. Research Quarterly for Exercise and Sport, 78(2), 79-89. https://doi.org/10.1080/02701367.2007.10599406

Uphill, M. A., McCarthy, P. J., \& Jones, M. (2009). Getting a grip on emotion regulation in sport: Conceptual foundations and practical application. In S. D. Mellalieu \& S. Hanton (Eds.), Advances in applied sport psychology: A review (pp. 162-194). Abingdon, England: Routledge.

Van Cutsem, J., Marcora, S., De Pauw, K., Bailey, S., Meeusen, R., \& Roelands, B. (2017). The 


\section{SELF-REGULATION IN ENDURANCE SPORTS}

effects of mental fatigue on physical performance: A systematic review. Sports Medicine, 47, 1569-1588. https://doi.org/10.1007/s40279-016-0672-0

Vast, R. L., Young, R. L., \& Thomas, P. R. (2010). Emotions in sport: Perceived effects on attention, concentration, and performance. Australian Psychologist, 45, 132-140. https://doi.org/10.1080/00050060903261538

Venhorst, A., Micklewright, D., \& Noakes, T. D. (2017). Towards a three-dimensional framework of centrally regulated and goal-directed exercise behaviour: a narrative review. British Journal of Sports Medicine. https://doi.org/10.1136/bjsports-2016-096907

Vohs, K. D., \& Baumeister, R. F. (Eds.). (2016). Handbook of self-regulation: Research, theory, and applications (3rd ed). New York, NY: Guilford Press.

Wagstaff, C. R. D. (2014). Emotion regulation and sport performance. Journal of Sport \& Exercise Psychology, 36, 401-412. https://doi.org/10.1123/jsep.2013-0257

Wallace, P. J., McKinlay, B. J., Coletta, N. A., Vlaar, J. I., Taber, M. J., Wilson, P. M., \& Cheung, S. S. (2017). Effects of motivational self-talk on endurance and cognitive performance in the heat. Medicine \& Science in Sports \& Exercise, 49, 191-199. https://doi.org/10.1249/MSS.0000000000001087

Webb, T. L., Miles, E., \& Sheeran, P. (2012). Dealing with feeling: A meta-analysis of the effectiveness of strategies derived from the process model of emotion regulation. Psychological Bulletin, 138, 775-808. https://doi.org/10.1037/a0027600

Weinberg, R., Gould, D., \& Jackson, A. (1979). Expectations and performance: An empirical test of Bandura's self-efficacy theory. Journal of Sport Psychology, 1, 320-331. Retrieved from http://journals.humankinetics.com/jsep

Weinberg, R. S., Gould, D., Yukelson, D., \& Jackson, A. (1981). The effect of preexisting and manipulated self-efficacy on a competitive muscular endurance task. Journal of Sport \& Exercise Psychology, 3, 345-354. https://doi.org/10.1123/jsp.3.4.345

Whitehead, A. E., Jones, H. S., Williams, E. L., Rowley, C., Quayle, L., Marchant, D., \& Polman, R. C. (2017). Investigating the relationship between cognitions, pacing strategies and performance in $16.1 \mathrm{~km}$ cycling time trials using a think aloud protocol. Psychology of Sport and Exercise, 


\section{SELF-REGULATION IN ENDURANCE SPORTS}

34, 95-109. https://doi.org/10.1016/j.psychsport.2017.10.001

Williams, E. L., Jones, H. S., Sparks, S. A., Marchant, D. C., Midgley, A. W., \& McNaughton, L. R. (2015). Competitor presence reduces internal attentional focus and improves $16.1 \mathrm{~km}$ cycling time trial performance. Journal of Science and Medicine in Sport, 18, 486-491. https://doi.org/10.1016/j.jsams.2014.07.003

Williams, E. L., Jones, H. S., Sparks, S. A., Midgley, A. W., Marchant, D. C., Bridge, C. A., \& McNaughton, L. R. (2015). Altered psychological responses to different magnitudes of deception during cycling. Medicine \& Science in Sports \& Exercise, 47, 2423-2430. https://doi.org/10.1249/MSS.0000000000000694

Wood, R., \& Bandura, A. (1989). Social cognitive theory of organizational management. Academy of Management Review, 14, 361-384. https://doi.org/10.5465/AMR.1989.4279067

Zimmerman, B. J. (2000). Attaining self-regulation: A social cognitive perspective. In M. Boekaerts, P. R. Pintrich, \& M. Zeidner (Eds.), Handbook of self-regulation (pp. 13-39). San Diego, CA: Academic Press.

Zimmerman, B. J. (2002). Becoming a self-regulated learner: An overview. Theory Into Practice, 41, 64-70. https://doi.org/10.1207/s15430421 tip4102_2 